\title{
Comparison of the T-tubule system in adult rat ventricular and atrial myocytes, and its role in excitation-contraction coupling and inotropic stimulation
}

\author{
Ioannis Smyrnias ${ }^{a}$, Waltraud Mair ${ }^{a}$, Dagmar Harzheim ${ }^{a}$, Simon A. Walker ${ }^{a}$, \\ H. Llewelyn Roderick ${ }^{\mathrm{a}, \mathrm{b}, *}$, Martin D. Bootman ${ }^{\mathrm{a}, * *}$ \\ a Calcium Group, Laboratory of Molecular Signalling, The Babraham Institute, Babraham, Cambridge CB22 3AT, UK \\ ${ }^{\mathrm{b}}$ Department of Pharmacology, University of Cambridge, Tennis Court Road, Cambridge CB2 1PD, UK
}

\section{A R T I C L E I N F O}

\section{Article history:}

Received 14 July 2009

Received in revised form

25 September 2009

Accepted 5 October 2009

Available online 27 January 2010

\section{Keywords:}

Calcium

Ryanodine

Receptor

Cardiac

Myocyte

Contraction

Tubule

Sarcoplasmic reticulum

Endothelin

\begin{abstract}
A B S T R A C T
Narrow, tubular, inward projections of the sarcolemma ('T-tubules') are an established feature of adult mammalian ventricular myocytes that enables them to generate the whole-cell $\mathrm{Ca}^{2+}$ transients and produce coordinated contraction. Loss of T-tubules can occur during ageing and under pathological conditions, leading to altered cardiac excitation-contraction coupling. In contrast to adult ventricular cells, atrial myocytes do not generally express an extensive T-tubule system at any stage of development, and therefore rely on $\mathrm{Ca}^{2+}$ channels around their periphery for the induction of $\mathrm{Ca}^{2+}$ signalling and excitation-contraction coupling. Consequently, the characteristics of systolic $\mathrm{Ca}^{2+}$ signals in adult ventricular and atrial myocytes are temporally and spatially distinct. However, although atrial myocytes do not have the same regularly spaced convoluted T-tubule structures as adult ventricular cells, it has been suggested that a proportion of adult atrial cells have a more rudimentary tubule system. We examined the structure and function of these atrial tubules, and explored their impact on the initiation and recovery of $\mathrm{Ca}^{2+}$ signalling in electrically paced myocytes. The atrial responses were compared to those in adult ventricular cells that had intact T-tubules, or that had been chemically detubulated. We found that tubular structures were present in a significant minority of adult atrial myocytes, and were unlike the T-tubules in adult ventricular cells. In those cells where they were present, the atrial tubules significantly altered the on-set, amplitude, homogeneity and recovery of $\mathrm{Ca}^{2+}$ transients. The properties of adult atrial myocyte $\mathrm{Ca}^{2+}$ signals were different from those in adult ventricular cells, whether intact or detubulated. Excitation-contraction coupling in detubulated adult ventricular myocytes, therefore, does not approximate to atrial signalling, even though $\mathrm{Ca}^{2+}$ signals are initiated in the periphery of the cells in both of these situations. Furthermore, inotropic responses to endothelin-1 were entirely dependent on $\mathrm{T}$-tubules in adult ventricular myocytes, but not in atrial cells. Our data reveal that that the T-tubules in atrial cells impart significant functional properties, but loss of these tubular membranes does not affect $\mathrm{Ca}^{2+}$ signalling as dramatically as detubulation in ventricular myocytes.
\end{abstract}

(C) 2009 Elsevier Ltd. All rights reserved.

\section{Introduction}

The heart is triggered to contract and pump blood to the lungs and body each time a depolarising action potential passes from the sinoatrial node to the conductive cells and contractile myocytes of the heart. At the cellular level, this process of excitation-contraction coupling is driven by an elevation of cytosolic $\mathrm{Ca}^{2+}[1]$. Depolarisation of a cardiac myocyte causes opening of

\footnotetext{
* Corresponding author at: Calcium Group, Laboratory of Molecular Signalling, The Babraham Institute, Babraham, Cambridge CB22 3AT, UK. Tel.: +44 1223496000.

** Corresponding author. Tel.: +44 1223496000.

E-mail addresses: llewelyn.roderick@bbsrc.ac.uk (H.L. Roderick), martin.bootman@bbsrc.ac.uk (M.D. Bootman).
}

L-type voltage-operated $\mathrm{Ca}^{2+}$ channels (VOCCs) on the sarcolemma, and a consequent influx of $\mathrm{Ca}^{2+}$ from the extracellular space. The $\mathrm{Ca}^{2+}$ ions that enter through the L-type VOCCS diffuse across a short inter-membrane space, the dyadic cleft, and activate clusters of $\mathrm{Ca}^{2+}$ release channels (ryanodine receptors; RyRs), which are embedded in the adjacent membrane of the sarcoplasmic reticulum (SR) [2]. RyRs permit $\mathrm{Ca}^{2+}$ ions stored within the SR to enter the cytosol, thereby substantially amplifying the initial $\mathrm{Ca}^{2+}$ influx signal; a process known as $\mathrm{Ca}^{2+}$-induced $\mathrm{Ca}^{2+}$ release (CICR). The $\mathrm{Ca}^{2+}$ ions released through the RyRs diffuse out of the dyadic cleft and engage the myofilaments consequently triggering contraction. Alteration of this precise coupling machinery causes unwarranted $\mathrm{Ca}^{2+}$ signals with pathological potential $[2,3]$.

The mammalian heart is comprised of two atrial and two ventricular chambers. The myocytes within these chambers share 
many structural and functional features, but they are not exactly alike [4]. A key feature of adult ventricular myocytes is their 'transverse-tubule' system (T-tubules); narrow $(\sim 200 \mathrm{~nm})$ inward projections of the sarcolemma [5,6]. In adult mammalian ventricular myocytes, T-tubules are present every $\sim 1.8 \mu \mathrm{m}$ along the longitudinal length of the cells (at the Z-disks), and can have complex branched morphologies, with both transverse and longitudinal segments of varying lengths [7]. Since they are physically and electrically contiguous with the sarcolemma around the circumference of myocytes, T-tubules convey the action potential deep into the cells. L-type VOCCs are expressed largely on T-tubule membranes, so the trigger $\mathrm{Ca}^{2+}$ signal that activates CICR occurs in the proximity of T-tubule membranes [8]. The regular T-tubule spacing within ventricular myocytes allows CICR to be activated simultaneously throughout the cells. The resultant homogenous global $\mathrm{Ca}^{2+}$ transient is necessary to ensure a coordinated cellular contraction. From this description, it is evident that T-tubules are an essential component of adult ventricular myocytes. In addition to L-type VOCCs, numerous other ion channels (e.g. for $\mathrm{K}^{+}, \mathrm{Na}^{+}$) and signalling proteins are expressed on T-tubule membranes [5].

Many laboratories have reported that adult atrial myocytes lack the well-developed T-tubule invaginations found in ventricular myocytes [5,9], and therefore express L-type VOCCs solely on the sarcolemma around the circumference of the cells [4]. This means that action potentials can only trigger $\mathrm{Ca}^{2+}$ entry and CICR at the outer edge of an atrial myocyte. The distribution of RyRs in adult atrial cells appears to be similar to that in ventricular myocytes [10-12]. However, there is an important functional difference. Given that the L-type VOCCs are expressed in the sarcolemma, rather than on T-tubules, only a small fraction of the RyRs (the 'junctional RyRs'), around the circumference of the cells, is positioned to respond to the opening of the VOCCs [12-14]. $\mathrm{Ca}^{2+}$ signals in atrial myocytes therefore originate at L-type VOCCs around the periphery of the cells, and are locally amplified by the junctional RyRs in the subsarcolemmal space.

In many species, including rat $[11,15]$, guinea pig [16,17], cat $[12,18]$ and human [19], it has been demonstrated that the subsarcolemmal $\mathrm{Ca}^{2+}$ signal does not propagate fully, or at all, into the centre of atrial cells. Therefore, at the peak of the response following depolarisation, substantial $\mathrm{Ca}^{2+}$ gradients can be observed within atrial myocytes; the subsarcolemmal $\mathrm{Ca}^{2+}$ concentration can be hugely elevated with no effect deeper inside the cell. This is surprising given that clusters of RyRs are regularly spaced $\sim 2 \mu \mathrm{m}$ apart within a 3-dimensional lattice that runs throughout every atrial cell $[10,11]$. It could be expected that RyRs would convey the subsarcolemmal $\mathrm{Ca}^{2+}$ signal deep into a myocyte via CICR. However, without the addition of a positive inotropic stimulus, the non-junctional RyRs in the centre of atrial myocytes can be largely unresponsive [20]. The significance of this spatially heterogeneous response is that under basal conditions, the $\mathrm{Ca}^{2+}$ signal does not reach the interior of the cell where the myofibrils are located. Consequently, the contraction of the cells is slight compared to ventricular myocytes [13].

Although there is wide agreement that adult atrial myocytes do not possess the extensive T-tubule network found in their ventricular counterparts, it has been proposed that they express a more rudimentary transverse-axial tubular network [21-25]. It has been presumed that this tubular system would influence atrial $\mathrm{Ca}^{2+}$ signalling and excitation-contraction coupling [25], but there is limited functional data in support of this notion. In this study, we characterised the T-tubules within adult rat ventricular and atrial myocytes, and examined the effect of their presence on the characteristics of $\mathrm{Ca}^{2+}$ signalling and responses to cardioactive hormones. For comparison, we examined $\mathrm{Ca}^{2+}$ signalling in control myocytes with an intact tubular system and cells that had been detubulated using an established technique involving osmotic swelling [26,27].

\section{Materials and methods}

\subsection{Reagents}

Collagenase type II was obtained from Worthington Biochemical Corporation. Endothelin-1 was purchased from Calbiochem. Isoproterenol and salts for extracellular solutions were purchased from Sigma-Aldrich or BDH. $\mathrm{Ca}^{2+}$-sensitive indicators were purchased from Invitrogen. Wistar rats were obtained from Harlan UK.

\subsection{Myocyte isolation and detubulation}

Adult atrial and ventricular myocytes were isolated as described previously [11]. In brief, male Wistar rats weighing approximately $250 \mathrm{~g}$ were anaesthetised in a $\mathrm{CO}_{2}$ chamber, and then killed by cervical dislocation. The heart was then dissected from the thorax and positioned on a modified Langendorff apparatus and perfused in a retrograde manner with HEPES buffer solution $(\mathrm{NaCl}$ $135 \mathrm{mM}$, $\mathrm{KCl} 5 \mathrm{mM}, \mathrm{CaCl}_{2} 1 \mathrm{mM}$, HEPES $10 \mathrm{mM}$, glucose $10 \mathrm{mM}$ and $\mathrm{MgCl} 20.4 \mathrm{mM}, \mathrm{pH} 7.35$ ) at $37^{\circ} \mathrm{C}$ for $4 \mathrm{~min}$. This was followed by perfusion with a low $\mathrm{Ca}^{2+}$ buffer solution $(\mathrm{NaCl} 120 \mathrm{mM}, \mathrm{KCl}$ $5 \mathrm{mM}, \mathrm{CaCl}_{2} 80 \mu \mathrm{M}$, HEPES $10 \mathrm{mM}$, taurine $20 \mathrm{mM}$, glucose $20 \mathrm{mM}$, $\mathrm{MgSO}_{4} 5 \mathrm{mM}$, NTA $5.5 \mathrm{mM}$ and sodium pyruvate $5 \mathrm{mM}$, pH 6.96) for $3.5 \mathrm{~min}$. Subsequent to the low $\mathrm{Ca}^{2+}$ solution, an enzyme buffer solution $\left(\mathrm{NaCl} 120 \mathrm{mM}, \mathrm{KCl} 5 \mathrm{mM}, \mathrm{CaCl}_{2} 35 \mu \mathrm{M}\right.$, HEPES $10 \mathrm{mM}$, taurine $20 \mathrm{mM}$, glucose $20 \mathrm{mM}, \mathrm{MgSO}_{4} 5 \mathrm{mM}$ and sodium pyruvate $5 \mathrm{mM}, \mathrm{pH} 7.4$ ) was recirculated through the apparatus for $10 \mathrm{~min}$. This solution also contained $319 \mathrm{IU} / \mathrm{ml}$ type II collagenase. Following dissociation of the myocytes, they were allowed to settle, and $\mathrm{Ca}^{2+}$ was reintroduced in an incremental manner to prevent intracellular $\mathrm{Ca}^{2+}$ overload and hypercontracture. The myocytes were kept at room temperature until ready for use. Only myocytes with no signs of deterioration and that had no spontaneous activity at rest were used for experiments. The myocytes were settled on poly-L-lysine-coated coverslips for $30 \mathrm{~min}$ before loading with a fluorescent $\mathrm{Ca}^{2+}$ indicator. All experiments were performed in accordance with the guidelines from the code of practice for humane killing under Schedule 1 of the Animals (Scientific Procedures) Act 1986.

Detubulation of myocytes was induced by osmotic swelling and retraction as described previously [27]. Briefly, cells were bathed with $1.5 \mathrm{M}$ formamide for $20 \mathrm{~min}$ at room temperature. Cells were then washed with formamide free solution $(\mathrm{NaCl} 113 \mathrm{mM}, \mathrm{KCl}$ $5 \mathrm{mM}, \mathrm{MgSO}_{4} 1 \mathrm{mM}, \mathrm{Na}_{2} \mathrm{HPO}_{4} 1 \mathrm{mM}$, sodium acetate $20 \mathrm{mM}$, glucose $10 \mathrm{mM}$, HEPES $10 \mathrm{mM}, \mathrm{CaCl} 20.5 \mathrm{mM} \mathrm{pH} 7.4$ ) for another 15-20 min prior to loading with a fluorescent $\mathrm{Ca}^{2+}$ indicator. In some experiments, untreated and detubulated cells were labelled with $10 \mu \mathrm{M}$ di-8-aminoaphthylethenylpyridinium (Di-8-ANNEPS) for 5-10 min, washed in control solution for $10 \mathrm{~min}$ and imaged using a Olympus FV1000 confocal microscope ( $488 \mathrm{~nm}$ excitation and detection at $>514 \mathrm{~nm}$ ). As described below, formamide-treated myocytes were viable, could be electrically paced and loaded with fluorescent $\mathrm{Ca}^{2+}$ indicators to the same degree as control cells. From these morphological and functional criteria, treatment of myocytes with formamide does not appear to have deleterious effects.

\subsection{Immunofluorescence}

Cardiomyocytes were allowed to settle on poly-L-lysine-coated coverslips and were subsequently fixed with $2 \%$ paraformaldehyde for $15 \mathrm{~min}$ at room temperature. Immunofluorescence and confocal was performed as described elsewhere [28]. Briefly, myocytes were permeabilised with PBS containing $0.2 \%$ Triton X-100 and were subsequently incubated with blocking buffer (PBS containing $0.1 \%$ Triton X-100, $5 \%$ goat serum and $10 \%$ BSA). Cells were then 
stained with antibodies against L-type $\mathrm{Ca}^{2+}$ channels (Calbiochem, cat. no. 681507; $1: 20$ dilution in antibody buffer-PBS containing $0.05 \%$ Triton X-100, 2\% goat serum and 10\% BSA), Ryanodine receptors (Calbiochem, cat. no. NR07; 1:20 dilution in antibody buffer) and Endothelin receptor A subtype (Alomone Labs. cat. no. AER-001; $1: 20$ dilution in antibody buffer). Appropriate secondary antibodies were used that were either goat anti-mouse or goat anti-rabbit conjugated with Alexa Fluor 488 or Alexa Fluor 568 (1:500 dilution of both). Cells were mounted in Vectashield containing DAPI on glass slides. Single slice and/or images stacks were obtained using an Olympus FV1000 confocal microscope. Raw image data were deconvolved using AutoDeblur software (Media Cybernetics). Co-localisation analysis (dependency of pixels to each other in dual-channel images) was performed by determining Pearson's coefficient using JACoP tool within ImageJ software [29]. Pearson's coefficient values for double-stained cells were obtained for three different regions on each cell and pooled together $(+1$ implies complete positive correlation, 0 for no correlation and -1 for negative correlation).

\subsection{Confocal and photometry imaging}

In photometry experiments, cells were loaded with indo- 1 by incubation with the acetoxymethyl ester form of the indicator ( $3 \mu \mathrm{M}$ for $30 \mathrm{~min}$ at room temperature). The cells were then washed in fresh buffer and left for a further $30 \mathrm{~min}$ before use, to allow complete de-esterification. For laser scanning confocal microscopy experiments, cells were loaded with fluo- 4 using a similar procedure to that for indo-1, except that the myocytes were incubated with $4 \mu \mathrm{M}$ fluo- 4 acetoxymethyl ester for $30 \mathrm{~min}$ at room temperature.

For the photometry recordings, simultaneous measurements of $\mathrm{Ca}^{2+}$ and contraction were made using a Photon Technology International RatioMaster system with two photomultiplier detectors (for indo-1 fluorescence) and an edge detection system (for contraction) fitted on inverted microscope (Olympus IX71). Coverslips bearing indo-1-loaded myocytes were placed on the stage of the microscope and superfused with HEPES buffer solution containing $1 \mathrm{mM} \mathrm{CaCl}_{2}$. The cells were stimulated with a potential difference of $100 \mathrm{~V}$ at $0.33 \mathrm{~Hz}$ via a pair of platinum field electrodes placed equidistant from the cell. The pacing frequency was $0.33 \mathrm{~Hz}$. Indo- 1 was excited using $360 \mathrm{~nm}$ light, and the fluorescence emission at 405 and $490 \mathrm{~nm}$ was sampled using two independent photomultiplier detectors every $10 \mathrm{~ms}$. The background fluorescence at 405 and $490 \mathrm{~nm}$ emission was determined from fields of view without cells immediately after each measurement, and this was subsequently subtracted from the respective experimental records by the software. The cells were paced continually throughout an experiment. To reduce bleaching of the indicator, indo-1 fluorescence was sampled discontinuously (30 s illumination and recording period followed by $30 \mathrm{~s}$ without illumination). The fluorescence emission ratio $(405 \mathrm{~nm} / 490 \mathrm{~nm})$ increases as $\mathrm{Ca}^{2+}$ is elevated. Contraction (cell shortening) was simultaneously measured with a video edge detector and recorded using the PTI software mentioned above. The fractional shortening was calculated as the difference between the maximum in cell length at the end of the diastolic phase and the minimum cell length during each pacing cycle. The amplitude of contraction was averaged for each 30 s recording interval.

For the line-scanning confocal recordings, coverslips bearing fluo-4-loaded myocytes were placed on the stage of an inverted microscope (Olympus FV1000) and superfused with HEPES buffer solution containing $1 \mathrm{mM} \mathrm{CaCl}_{2}$. Myocytes were scanned at $580 \mathrm{~Hz}$ along a line perpendicular to their long axis. The line was positioned to avoid the nuclear area. Each recording lasted for approximately four contraction cycles. Data was analysed off-line with Image J (NIH, US).
All experiments were performed at room temperature $\left(20-22^{\circ} \mathrm{C}\right)$, since cell viability and dye loading is prolonged at this temperature. Prior to starting experiments, all cells were paced for a brief period to establish a steady-state $\mathrm{Ca}^{2+}$ response. Generally, it took between 10 and 20 depolarisations to reach equilibrium.

\subsection{Statistical analysis}

Results are expressed as mean \pm standard error. Statistical significance was determined using Student's $t$-tests. The ' $p$ ' value is indicated for results that were statistically significant (i.e. where $p<0.05$ ). The number of cells (' $n$ ') used in each experiment is indicated in the figures.

\section{Results}

\subsection{Distribution of L-type VOCCs and RyRs in adult ventricular and atrial myocytes}

To explore the relative roles of T-tubules in adult ventricular and atrial myocyte EC-coupling, we examined the structure of these cells before and after chemical detubulation. L-type VOCCs and RyRs are the principal $\mathrm{Ca}^{2+}$ channels underlying EC-coupling. Their relative distributions in adult ventricular and atrial myocytes are illustrated in Fig. 1. Type 2 RyRs exhibited a regular pattern of striations perpendicular to the long axis of both cell types. The distribution of RyRs was similar in atrial and ventricular myocytes, apart from an obvious extra component of RyR immunostaining around the periphery of the atrial cells that was not evident for ventricular cells. This peripheral population of junctional RyRs sits closest to the L-type VOCCs in the atrial sarcolemma, and is responsible for the initial $\mathrm{Ca}^{2+}$ responses observed during atrial EC-coupling $[11,30]$.

The distributions of L-type VOCCs in atrial and ventricular myocytes were distinctive (Fig. 1Aii and Cii). Ventricular myocytes displayed a striated pattern of L-type VOCs that could be entirely superimposed on that of the RyR distribution (Fig. 1Aiii), and colocalisation analysis suggested a high degree of spatial overlap (Fig. 1E). The spatial correlation between L-type VOCCs and RyRs in ventricular myocytes is also evident from the immunofluorescence intensity profiles shown in Fig. 1Aiv. These data are consistent with the well-known distribution of RyRs and L-type VOCCs in ventricular myocytes, which have T-tubules regularly spaced along their length [31].

In contrast, for atrial myocytes, the L-type VOCC immunostaining was significant around their periphery, with only small patches of staining within the centre of the cells. Co-localisation analysis concurred with the notion of limited RyR and L-type VOCC overlap (Fig. 1E). The lack of striated L-type VOCC staining in atrial myocytes is consistent with previous reports which have concluded that these cells do not possess an extensive T-tubule system [4]. However, although there was no striated pattern of L-type VOCC distribution in atrial myocytes, in a minority of cells there were irregular strands of L-type VOCC immunostaining consistent with the notion of a tubule. One such example is depicted by the arrow in Fig. 1Cii. The intensity profile derived from a line running across this region indicates the substantial density of immunostaining within this strand, and also the fact that it was correlated with a RyR striation (Fig. 1Civ).

Orchard and colleagues have established a method for detubulating myocytes using brief application of $1.5 \mathrm{M}$ formamide solution to cause a rapid osmotic shock $[26,27]$. Formamide treatment did not alter the distributions of type 2 RyRs or L-type VOCCs in atrial myocytes (Fig. 1Di-iii), nor the striated appearance of RyR or Ltype VOCC immunostaining in ventricular myocytes (Fig. 1Bi-iii). Co-localisation analysis revealed that the detubulation process did 

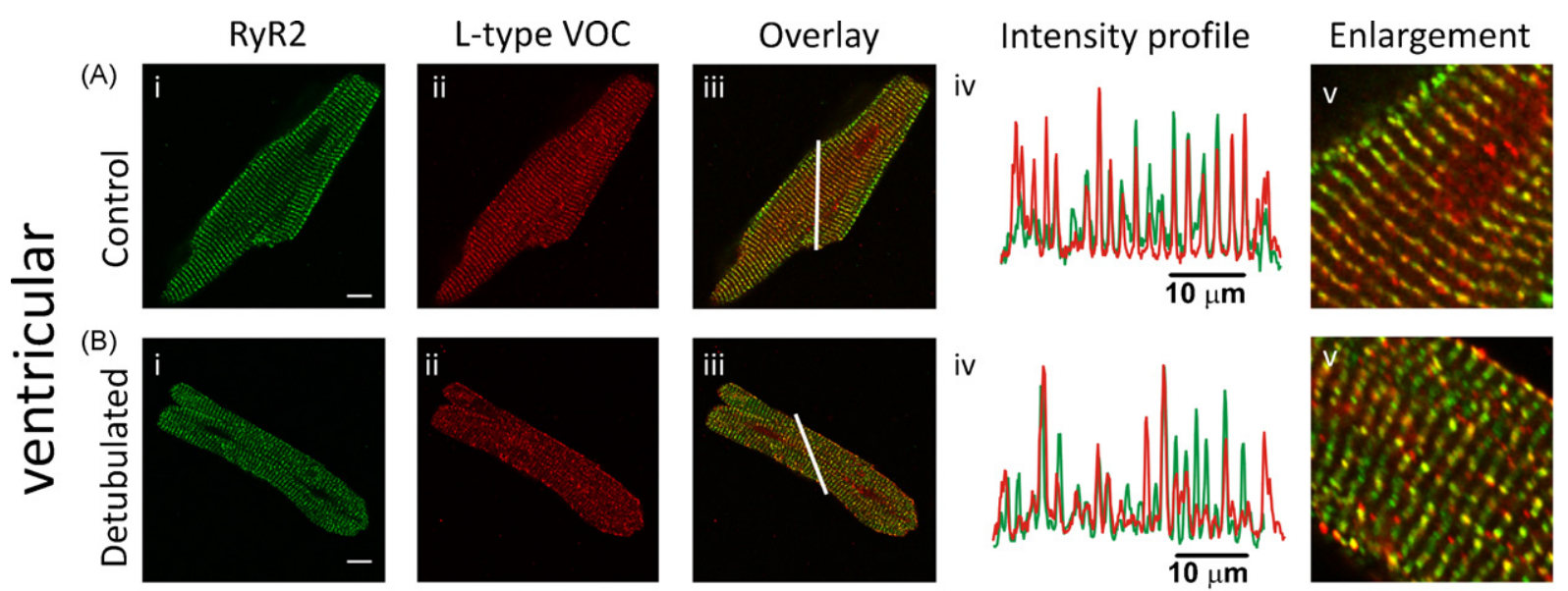

iv
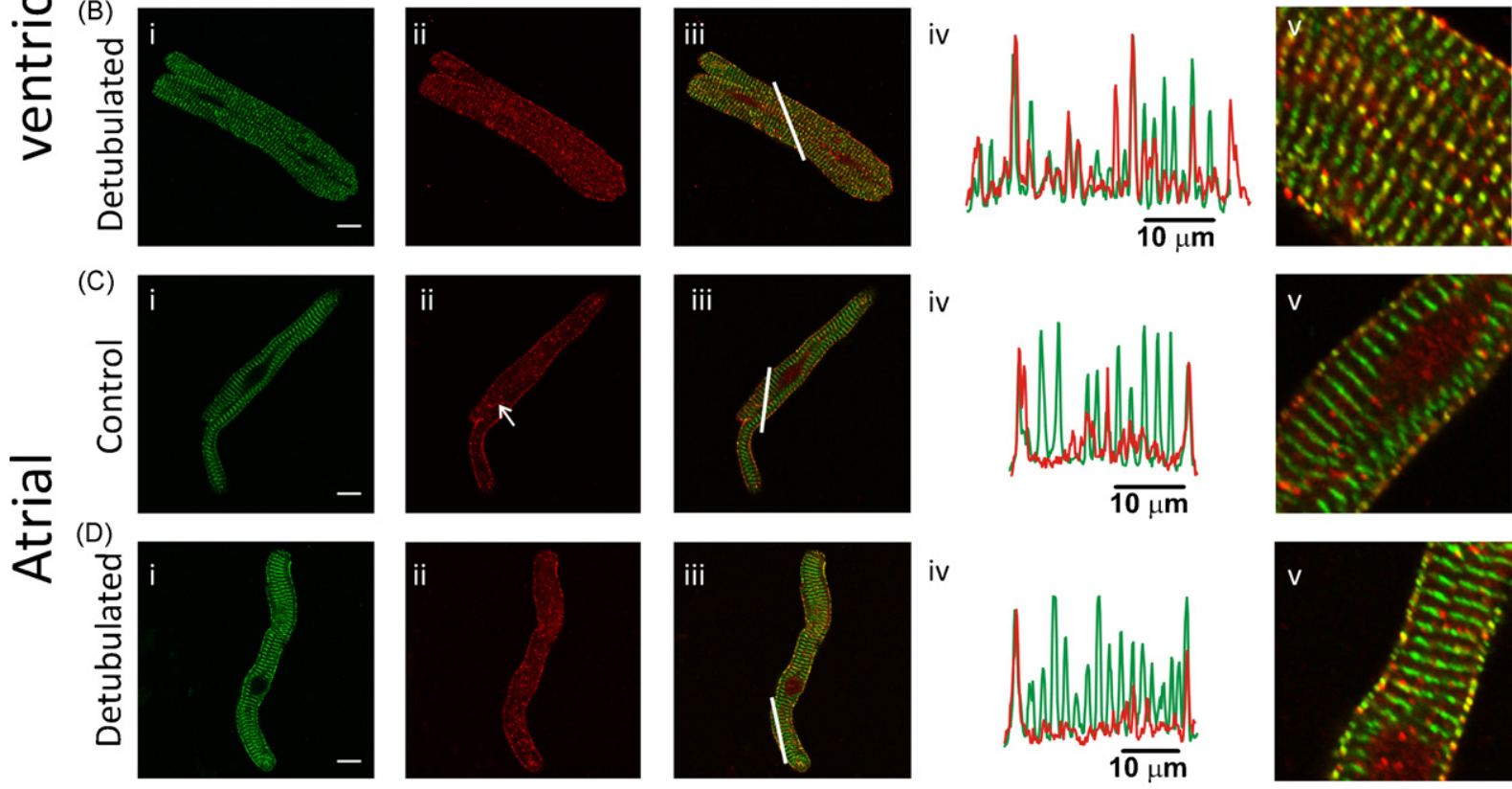

iv
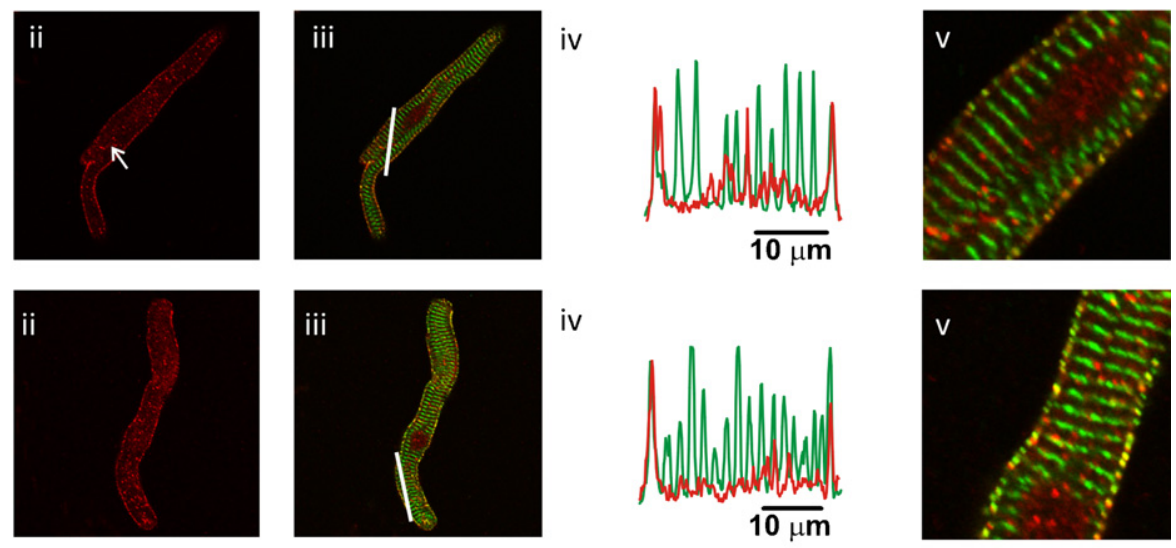

(E)

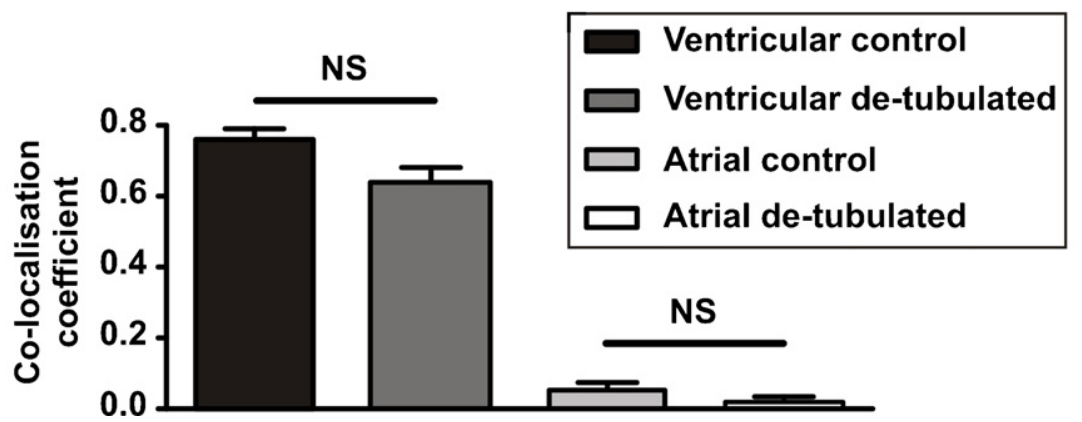

Fig. 1. Localisation of RyRs and L-type VOCCs in ventricular and atrial myocytes. The images in panels A-D depict single ventricular (A and B) or atrial (C and D) myocytes immunostained for type 2 RyRs or L-type VOCCs, either with or without chemical detubulation. The scale bars represent $10 \mu \mathrm{m}$. The intensity profiles (Aiv-Div) were obtained by measuring the intensity of fluorescent antibody labelling across the cellular regions depicted by the white lines in the overlay images. The white bars in the cell images represent $10 \mu \mathrm{m}$. Panel $\mathrm{E}$ shows a quantitative measure of RyR/L-type VOCC co-localisation in control and detubulated myocytes. The data are representative of $>50$ cells for each condition, sampled from at least three independent preparations. NS indicates not significant ( $p>0.05$; Student's $t$-test).

not significantly affect the spatial overlap of RyRs and L-type VOCCs in either ventricular or atrial myocytes (Fig. 1E).

\subsection{Ventricular and atrial adult myocytes possess a T-tubule system}

To more closely examine the ventricular T-tubule system, and any putative tubular structures within atrial myocytes, cells were stained with the lipophilic fluorescent indicator Di-8-ANNEPS, which specifically intercalates within the plasma membrane. Typical examples of Di-8-ANNEPS-stained ventricular and atrial myocytes are shown in Fig. 2. Regular transverse striations were observed in ventricular myocytes, as was depicted for RyRs in Fig. $1 \mathrm{Ai}-\mathrm{ii}$. The spacing of the Di-8-ANNEPS striations $(\sim 1.8-2 \mu \mathrm{m})$ matched that observed for RyR and L-type VOCC immunostain- ing (Fig. 1); consistent with those $\mathrm{Ca}^{2+}$ channels being localised adjacent to the T-tubule membranes. Treatment of cells with formamide before Di-8-ANNEPS application dramatically reduced the appearance of internal striations (Fig. 2B). The sarcolemma was intact, with short membrane protrusions emanating from it, but there was a marked reduction of the regular striated staining (Fig. 2Bii). The internal Di-8-ANNEPS labelling within control and detubulated ventricular myocytes is shown in a more quantitative form in Fig. 2Aiii and Biii. The graphs depict the intensity of Di-8-ANNEPS staining assessed along a line running the longitudinal length of the cells. The intensity peaks indicate the presence of T-tubule membranes. Comparison of the Di-8-ANNEPS intensity profiles in control ventricular myocytes (Fig. 2Aiii) and that obtained after formamide treatment (Fig. 2Biii) clearly shows the dramatic loss of T-tubules. 

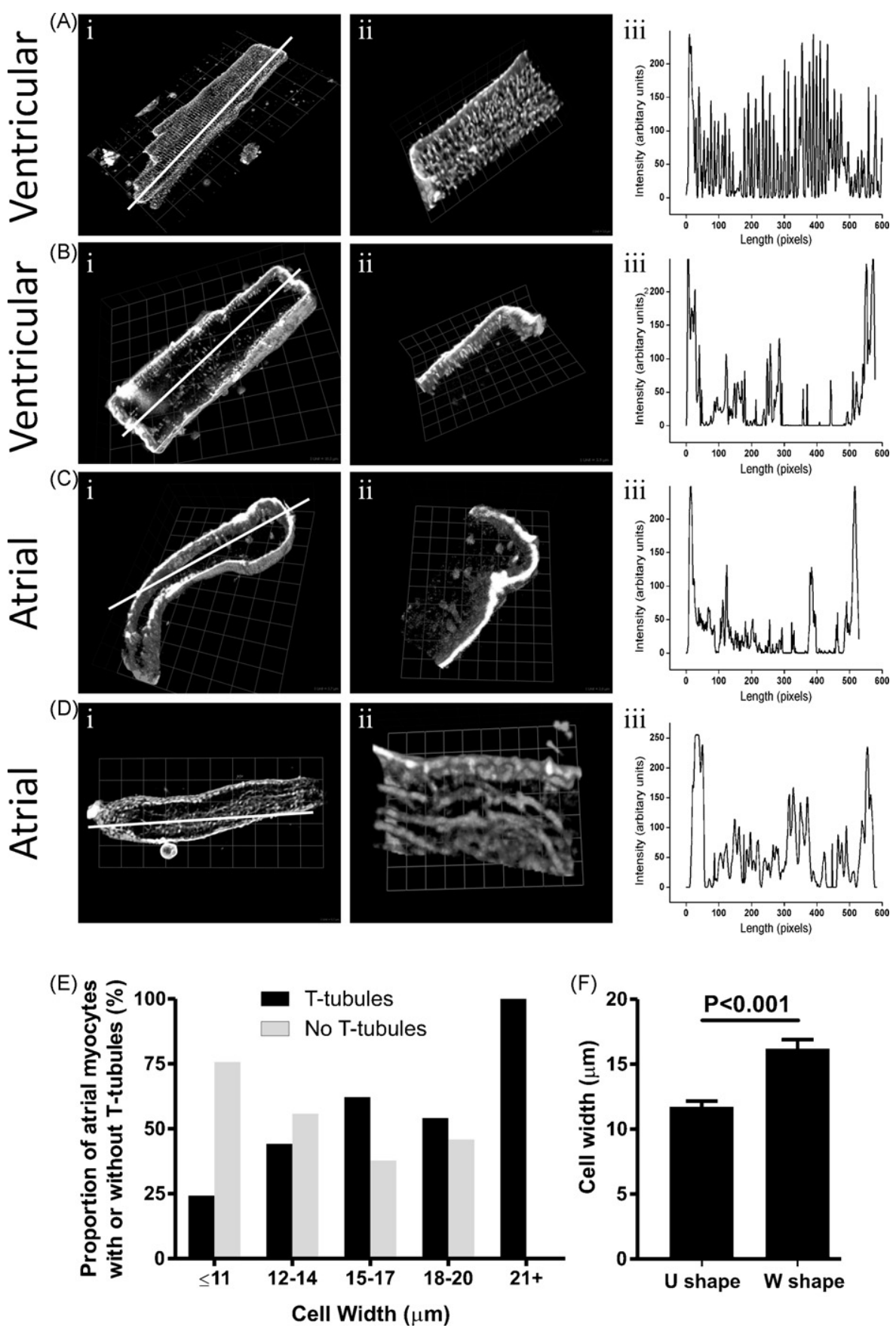

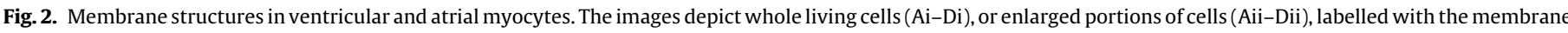

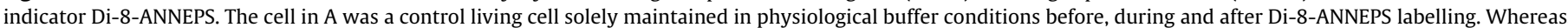

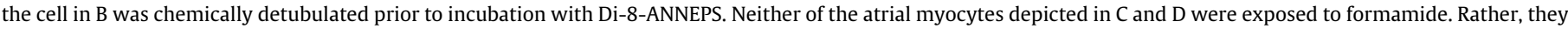

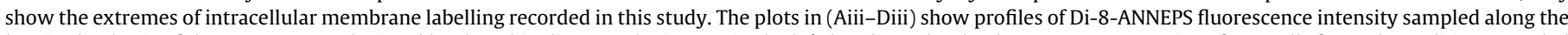

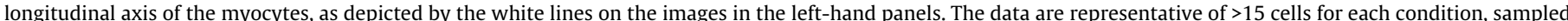

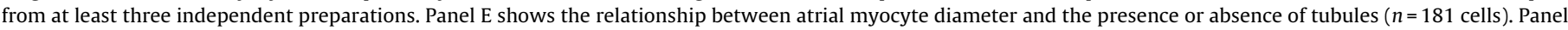
F depicts the relationship between cell diameter and the pattern of $\mathrm{Ca}^{2+}$ response (' $U$ '- or ' $\mathrm{W}$ '-shaped) observed in atrial myocytes ( $n=42$ cells).

Whereas the T-tubule distribution in ventricular myocytes was highly consistent from cell to cell, the pattern of Di-8-ANNEPS staining in atrial myocytes was more variable. Fig. $2 \mathrm{C}$ and $\mathrm{D}$ depict two representative atrial myocytes that show the extremes of Di-8-ANNEPS labelling observed in this study. In one cell, there was a distinct paucity of Di-8-ANNEPS staining, with only a few sporadic structures with variable shapes and diameters (Fig. 2C). The Di-8-ANNEPS intensity profile along the length of this atrial myocyte resembled that of formamide-treated ventricular myocytes (c.f. Fig. 2Biii and Ciii). This was the most commonly observed pattern of Di-8-ANNEPS labelling in atrial myocytes $(82 \% ; n=17)$. In a minority of atrial myocytes, such as the one depicted in Fig. 2Di, there was a substantial membranous system, which largely appeared to occupy the centre of the cell but was also observed in close proximity to the sarcolemma (Fig. 2Di and ii). These tubules had an irregular distribution, with short transverse branches and substantial longitudinal elements. The intensity profile of Di-8-ANNEPS staining shown in Fig. 2Diii illustrates the random distribution of tubular elements in this atrial myocyte. 
It has been previously suggested that the presence of T-tubules within atrial myocytes correlates with the diameter of the cells [25]. In the present study, we also observed a statistically significant difference in the width of atrial cells that possessed internal tubular membranes (Fig. 2E). The mean width of cells without tubules was $13.7 \pm 0.4 \mu \mathrm{m}(n=88)$, whereas cells with tubules had an average width of $16.6 \pm 0.4 \mu \mathrm{m}(n=93 ; p<0.001)$. All cells with a width greater than $20 \mu \mathrm{m}$ possessed tubules, consistent with the notion that larger myocytes rely on tubules to coordinate $\mathrm{Ca}^{2+}$ release from the SR within their central regions.

\subsection{Spatiotemporal properties of $\mathrm{Ca}^{2+}$ transients in ventricular and atrial myocytes}

The data presented in Fig. 2A illustrate the well-known T-tubule system within adult ventricular myocytes [26]. The presence of the tubules allows the action potential to activate L-type VOCCs, and their juxtaposed RyRs, throughout a ventricular cell leading to a homogenous global $\mathrm{Ca}^{2+}$ increase. An example of such a homogenous $\mathrm{Ca}^{2+}$ rise, recorded using confocal line-scanning, is depicted in Fig. 3A. It is evident that electrical depolarisation caused a rapid $\mathrm{Ca}^{2+}$ increase that occurred along the whole length of the scanned line. The kinetics of the $\mathrm{Ca}^{2+}$ rise within different regions of the cell is shown quantitatively by the traces in Fig. 3A. There was no appreciable delay in any part of the myocyte. In contrast, with cells that had been detubulated, the pattern of electrically evoked $\mathrm{Ca}^{2+}$ response was highly variable. No ventricular myocytes $(n=35)$ displayed homogenous $\mathrm{Ca}^{2+}$ transients following the detubulation protocol. Rather, they displayed $\mathrm{Ca}^{2+}$ waves with variable points of origin. In the majority of cases $(n=16 / 26)$, the detubulated ventricular myocytes showed ' $U$ '-shaped $\mathrm{Ca}^{2+}$ responses, where two $\mathrm{Ca}^{2+}$ waves initiated at the edges of a cell and then propagated inwards. An example of such a ' $U$ '-shaped $\mathrm{Ca}^{2+}$ transient in a detubulated ventricular myocyte is depicted in Fig. 3B. It is evident from the line-scan image and the corresponding traces that the $\mathrm{Ca}^{2+}$ signal was spatially and temporally heterogeneous. The central portion of the cell took $>100 \mathrm{~ms}$ to respond. Furthermore, the amplitude of the $\mathrm{Ca}^{2+}$ transient and its rate of rise were substantially reduced following detubulation. In other detubulated ventricular cells, a single $\mathrm{Ca}^{2+}$ wave was observed, which initiated at one edge of the cell and propagated all, or part way, across the cell (Fig. 4B). Alternatively, the $\mathrm{Ca}^{2+}$ signal in detubulated cells had multiple initiation sites, often with continual stochastic $\mathrm{Ca}^{2+}$ spark activity (see below).

In contrast to adult ventricular myocytes, the majority of atrial cells ( $85 \% ; n=40)$ displayed a ' $U$ '-shaped $\mathrm{Ca}^{2+}$ transient under control conditions (Fig. 3C). The $\mathrm{Ca}^{2+}$ signal initiated at the peripheral edges of the cell, and subsequently propagated inwards with a declining amplitude and rate of rise. Such atrial responses were similar in appearance to those observed in some detubulated ventricular myocytes, except that the atrial $\mathrm{Ca}^{2+}$ signal was typi-
(A) $\widehat{0}$

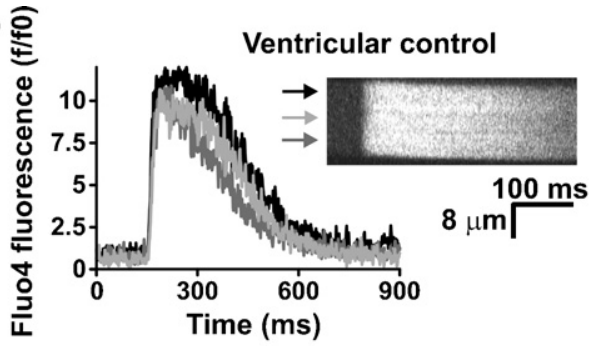

(C)

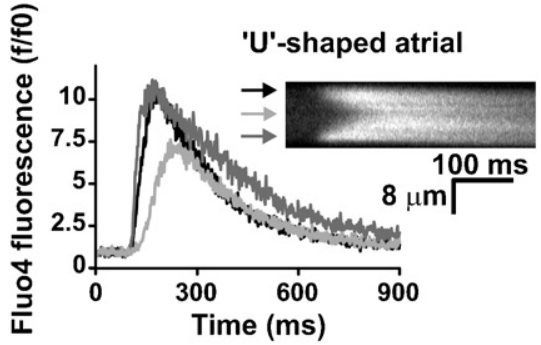

(E)
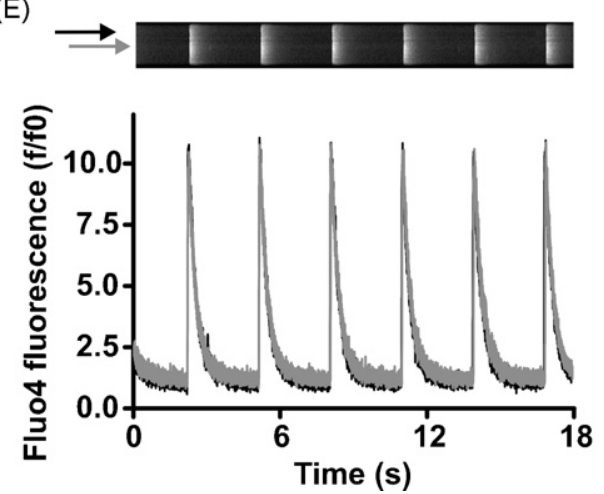

(B) $\widehat{0}$

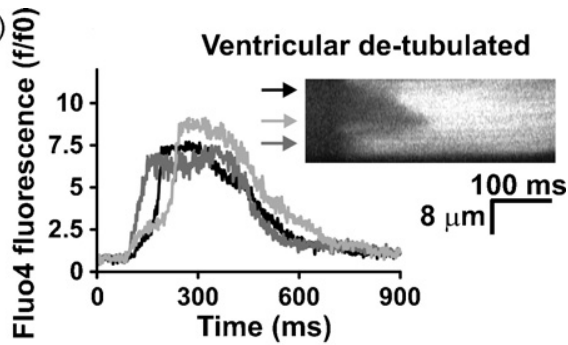

(D) 운

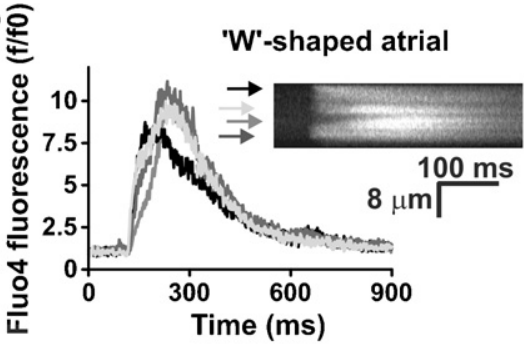

(F)
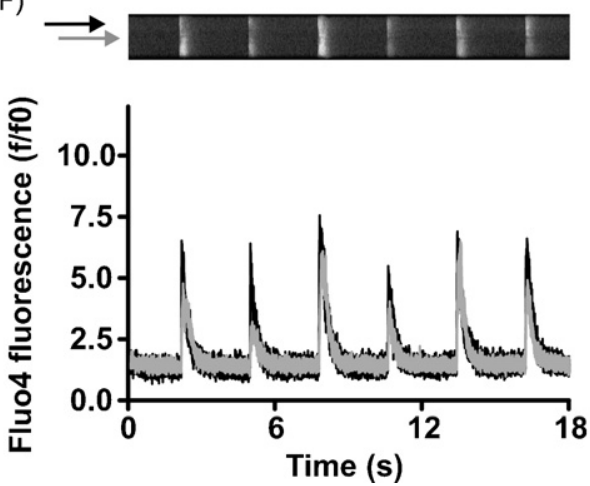

Fig. 3. $\mathrm{Ca}^{2+}$ transients in ventricular and atrial myocytes with or without T-tubules. Panels A-D depict the temporal and spatial properties of single depolarisation-evoked $\mathrm{Ca}^{2+}$ transients in: (A) control ventricular myocyte; (B) detubulated ventricular myocyte; (C) atrial myocyte with a ' $\mathrm{U}$ '-shaped $\mathrm{Ca}^{2+}$ signal; (D) atrial myocyte with an internal initiation site. The traces were obtained by sampling fluo-4 intensity along the line-scan images, as depicted by the correspondingly coloured arrows. The data are representative of $>10$ cells for each condition, sampled from at least three independent preparations. Panels $\mathrm{E}$ and $\mathrm{F}$ illustrate repetitive $\mathrm{Ca}^{2+}$ transients in single control (E) or detubulated $(\mathrm{F})$ ventricular myocytes. The data are representative of $>10$ cells for each condition, sampled from at least three independent preparations. 

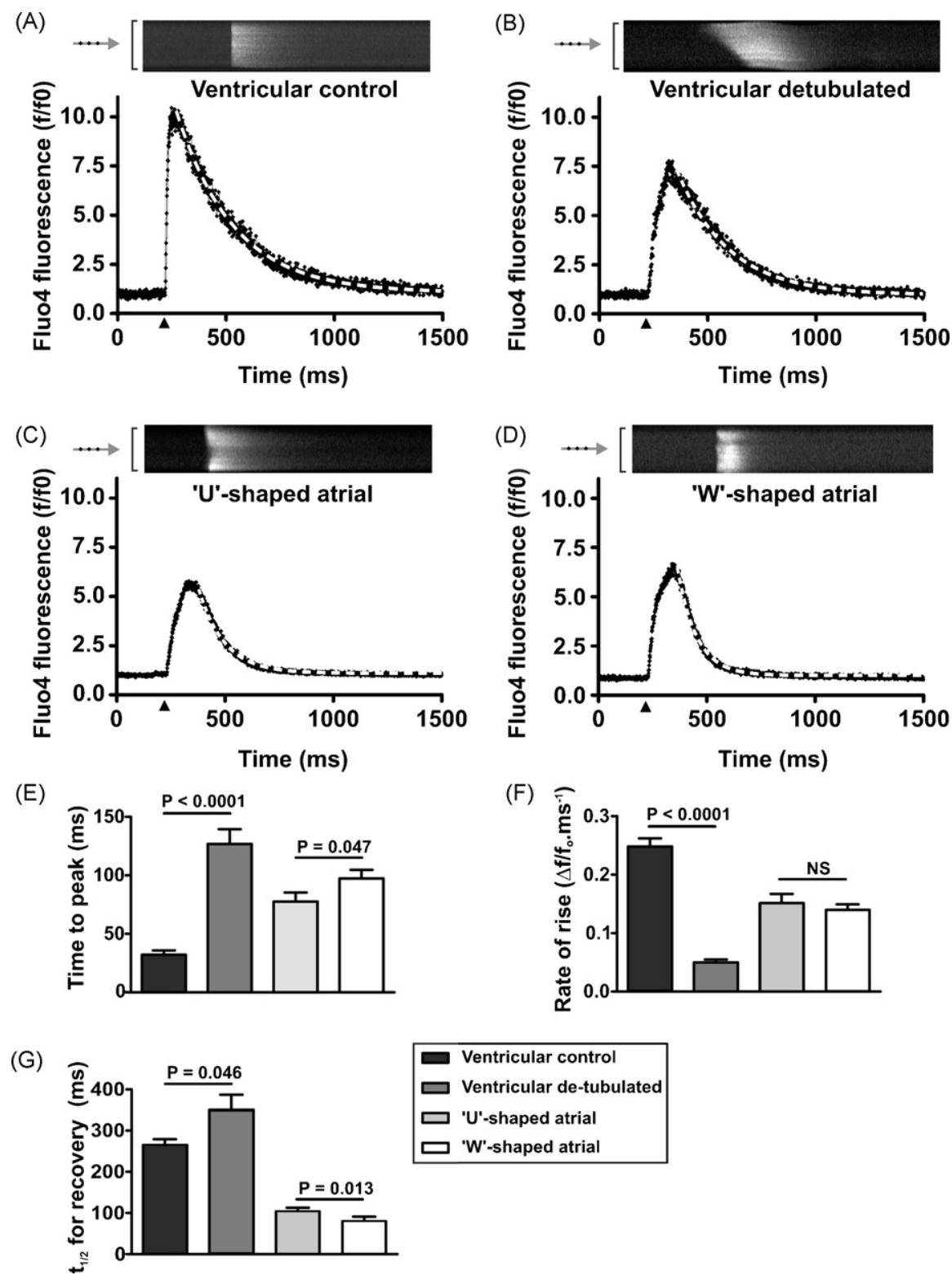

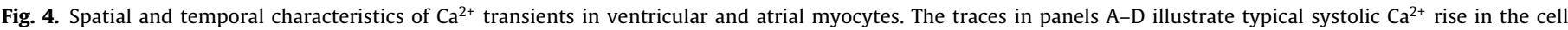

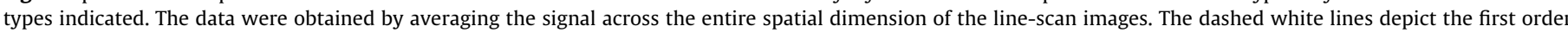

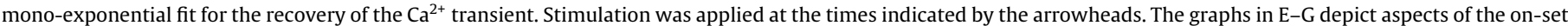

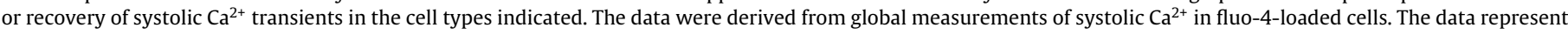
mean $\pm \operatorname{SEM}$ ( $n=16$ for each condition).

cally more symmetrical and had a faster on-set and recovery (cf. Fig. 3B and C). In a minority of atrial cells (15\%; $n=40)$, the $\mathrm{Ca}^{2+}$ signal simultaneously initiated in the periphery and also at one or two central regions within the cell (collectively termed ' $W$ 'shaped $\mathrm{Ca}^{2+}$ transients). An example of an atrial cell response with a central initiation site is depicted in Fig. 3D. Typical for atrial myocytes with central initiation sites, the $\mathrm{Ca}^{2+}$ signal in this cell appeared to be more spatially homogenous at its on-set. In addition, the amplitude of the $\mathrm{Ca}^{2+}$ signal within the centre of the cell exceeded that of the periphery. Double-labelling of atrial myocytes with Di-8-ANNEPS and fluo-4, to monitor membrane structure and $\mathrm{Ca}^{2+}$ simultaneously, revealed that all atrial cells with one or more central initiation sites possessed clearly visible internal tubule structures (100\%; $n=7$; data not shown). Consistent with the correlation between cell width and the presence of T-tubules presented earlier (Fig. 2E), we observed that those cells displaying ' $\mathrm{W}$ '-shaped $\mathrm{Ca}^{2+}$ transients were signifi- cantly wider than their counterparts with 'U'-shaped responses (Fig. 2F).

As described above, detubulation of ventricular myocytes decreased the amplitude and increased the rise time of systolic $\mathrm{Ca}^{2+}$ transients. Furthermore, detubulation caused the $\mathrm{Ca}^{2+}$ signals within a paced ventricular cell to become more variable. With control ventricular myocytes, the amplitude of $\mathrm{Ca}^{2+}$ transients was typically consistent for the duration of stimulation, once cells had reached steady state (Fig. 3E). Furthermore, with control cells, there was no intracellular variation in the characteristics of the $\mathrm{Ca}^{2+}$ signal from beat-to-beat. In contrast, with detubulated cells, the amplitude of the $\mathrm{Ca}^{2+}$ signal varied substantially between depolarisations (Fig. 3F; 83\% of cells; $n=12$ ). Moreover, there was intracellular heterogeneity within the $\mathrm{Ca}^{2+}$ transients. This heterogeneity was less evident at the periphery of the cells, where the $\mathrm{Ca}^{2+}$ signals initiated, but often appeared as alternans within the centre of the detubulated cells. Such variation and alternans were 
not observed in the atrial cells (' $U$ '- or 'W'-shaped) used in this study.

The kinetic characteristics of the $\mathrm{Ca}^{2+}$ transients evoked in atrial myocytes and control or detubulated ventricular cells are depicted quantitatively in Fig. 4. The traces in Fig. 4A-D depict the average global $\mathrm{Ca}^{2+}$ change in four cells that were typical of those observed in this study. The recovery of ventricular (control or detubulated) and atrial (' $U$ '- or ' $W$ '-shaped) systolic $\mathrm{Ca}^{2+}$ transients could be fitted with a mono-exponential decay curve with an $\mathrm{R}^{2} \geq 0.96$ in all cases (typical fits are depicted by the dashed white lines in Fig. 4A-D), from which the half-time for decay was calculated.

It is evident that detubulation of ventricular myocytes had a marked repressive effect on both the time for $\mathrm{Ca}^{2+}$ transients to reach peak and their rate of rise, such that they were $\sim 5$-fold slower in both respects (Fig. 4E and F). In addition, the amplitude of systolic $\mathrm{Ca}^{2+}$ transients was significantly diminished in detubulated ventricular myocytes compared to control cells (average $F / F_{0} 5.2 \pm 0.4$ in detubulated versus $7.5 \pm 0.9$ in control; $n=20 ; p=0.02$ ). Although the bulk of detubulated ventricular cells and control atrial myocytes displayed spatially similar ' $U$ '-shaped $\mathrm{Ca}^{2+}$ transients, detubulation slowed the rise of ventricular $\mathrm{Ca}^{2+}$ signals so that they peaked significantly more slowly than in control atrial cells. Indeed, the kinetics for the on-set of atrial cell $\mathrm{Ca}^{2+}$ responses were intermediate between those of control and detubulated ventricular cells.

In those atrial myocytes that displayed central initiation sites, the time for the $\mathrm{Ca}^{2+}$ transient to peak was actually longer than in atrial cells with ' $U$ '-shaped responses (Fig. 4E). This could seem paraxodical, since the cells with central initiation sites appeared to have a greater degree of coordination during the on-set of their $\mathrm{Ca}^{2+}$ transients (Fig. 3D). However, the atrial cells with central initiation sites had $\mathrm{Ca}^{2+}$ transients that were $\sim 25 \%$ larger than responses in ' $U$ '-shaped atrial cells $(n=20)$. Furthermore, as depicted in Fig. 3D, the $\mathrm{Ca}^{2+}$ transients in myocytes with central initiation sites typically had a delayed peak due to the development of the $\mathrm{Ca}^{2+}$ signal within the centre of the cells. Therefore, the ' $W$ '-shaped $\mathrm{Ca}^{2+}$ transients in atrial cells gives larger systolic $\mathrm{Ca}^{2+}$ signals that initiate with greater homogeneity than their ' $U$ '-shaped counterparts, but they actually take longer to peak, due to the development of CICR within the centre of the cells.

Detubulation significantly slowed recovery of ventricular $\mathrm{Ca}^{2+}$ transients (Fig. 4G), even though detubulated cells had $\mathrm{Ca}^{2+}$ signals with lesser amplitudes. Atrial myocytes with 'W'-shaped $\mathrm{Ca}^{2+}$ signals displayed a faster rate of recovery than those with ' $U$ '-shaped $\mathrm{Ca}^{2+}$ transients (Fig. 4G). The expression of central initiation sites in atrial myocytes therefore gives rise to $\mathrm{Ca}^{2+}$ transients that are larger, but decay more rapidly. However, due to $\mathrm{Ca}^{2+}$ signals in tubulated atrial myocytes being larger, the absolute times for ' $U$ 'or 'W'-shaped $\mathrm{Ca}^{2+}$ signals to return to diastolic levels was not significantly different (data not shown).

In addition to having larger $\mathrm{Ca}^{2+}$ signals that decayed more rapidly, cells with ' $W$ '-shaped $\mathrm{Ca}^{2+}$ transients demonstrated more rapid reloading of the $\mathrm{SR}$ with $\mathrm{Ca}^{2+}$. This was demonstrated using an experimental protocol whereby the SR was depleted of $\mathrm{Ca}^{2+}$ using caffeine application, and the subsequent increase in systolic $\mathrm{Ca}^{2+}$ was monitored following caffeine wash-out [32]. For ventricular myocytes, this protocol demonstrated a significant reduction of the recovery of $\mathrm{SR} \mathrm{Ca}^{2+}$ loading in detubulated cells [32]. An example of the experimental paradigm used in this study is depicted in Fig. 5A. The cells were electrically paced to steady state, after which pacing was halted and caffeine $(10 \mathrm{mM})$ was applied. Following recovery of the caffeine-evoked $\mathrm{Ca}^{2+}$ transient, pacing was re-started. To prevent excessive illumination, and therefore avoid bleaching of fluo- $4, \mathrm{Ca}^{2+}$ signals were monitored at the specified intervals shown. The peak systolic $\mathrm{Ca}^{2+}$ level progressively increased as the cells were stimulated post-caffeine. Consistent with the findings of Orchard and colleagues [32], detubulation dramatically slowed
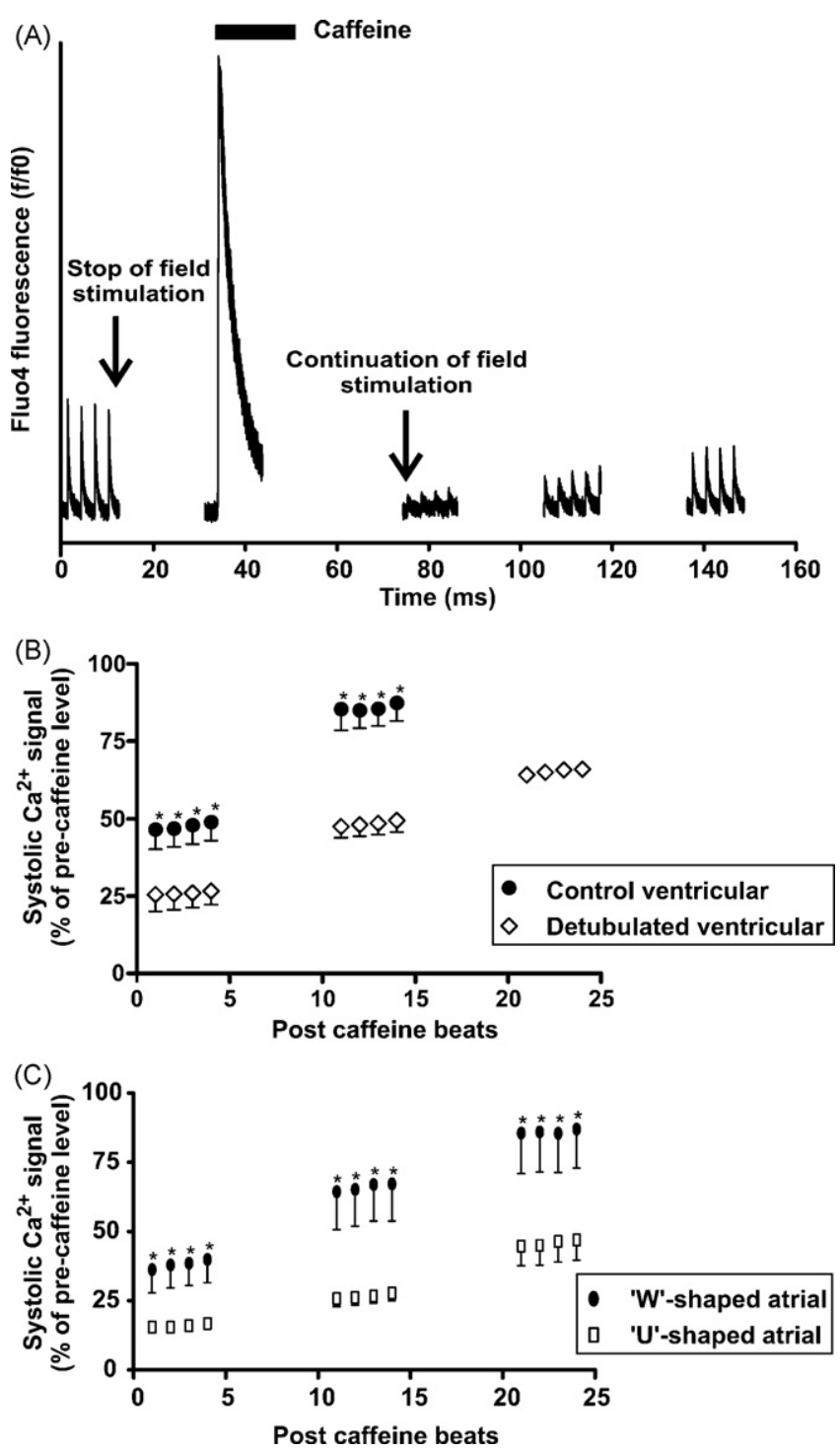

Fig. 5. Recovery of SR $\mathrm{Ca}^{2+}$ loading following depletion. Panel A depicts the experimental protocol used to examine SR reloading following caffeine-induced depletion. Panel B shows the normalised peak systolic $\mathrm{Ca}^{2+}$ level in control and detubulated ventricular myocytes following continuation of electrical pacing. The amplitude of the $\mathrm{Ca}^{2+}$ transients was normalised to the level seen prior to caffeine application. The data represent mean $\pm \operatorname{SEM}$ ( $n=8$ for each condition). Panel $C$ shows the normalised peak systolic $\mathrm{Ca}^{2+}$ level in tubulated ('W'-shaped) and non-tubulated ('U'-shaped) atrial myocytes following continuation of electrical pacing. The cells were designated into these categories based on the appearance of their electrically stimulated $\mathrm{Ca}^{2+}$ transients in line-scans obtained at steady state, prior to caffeine application. The amplitude of the $\mathrm{Ca}^{2+}$ transients was normalised to the level seen prior to caffeine application. The data represent mean $\pm \operatorname{SEM}(n=8$ for each condition). *Statistical significance $(p<0.001)$

the recovery of systolic $\mathrm{Ca}^{2+}$ signals in adult ventricular myocytes (Fig. 5B). Comparison of the responses in atrial cells with ' $U$ '- or 'W'-shaped $\mathrm{Ca}^{2+}$ transients revealed that the latter cells recovered significantly more rapidly (Fig. 5C), suggesting that the presence of the atrial T-tubule system enhances SR reloading.

It is also evident that the systolic $\mathrm{Ca}^{2+}$ transients recovered most rapidly in control ventricular myocytes (Fig. 5B). Whereas, the responses in atrial myocytes with ' $U$ '-shaped $\mathrm{Ca}^{2+}$ transients recovered the slowest (Fig. 5C). The systolic $\mathrm{Ca}^{2+}$ transients in detubulated ventricular myocytes and atrial cells with 'W'-shaped $\mathrm{Ca}^{2+}$ transients recovered over a similar time course, with $\sim 50-60 \%$ recovery after $\sim 10$ depolarisations (Fig. $5 B$ and $C$ ). 
(A)
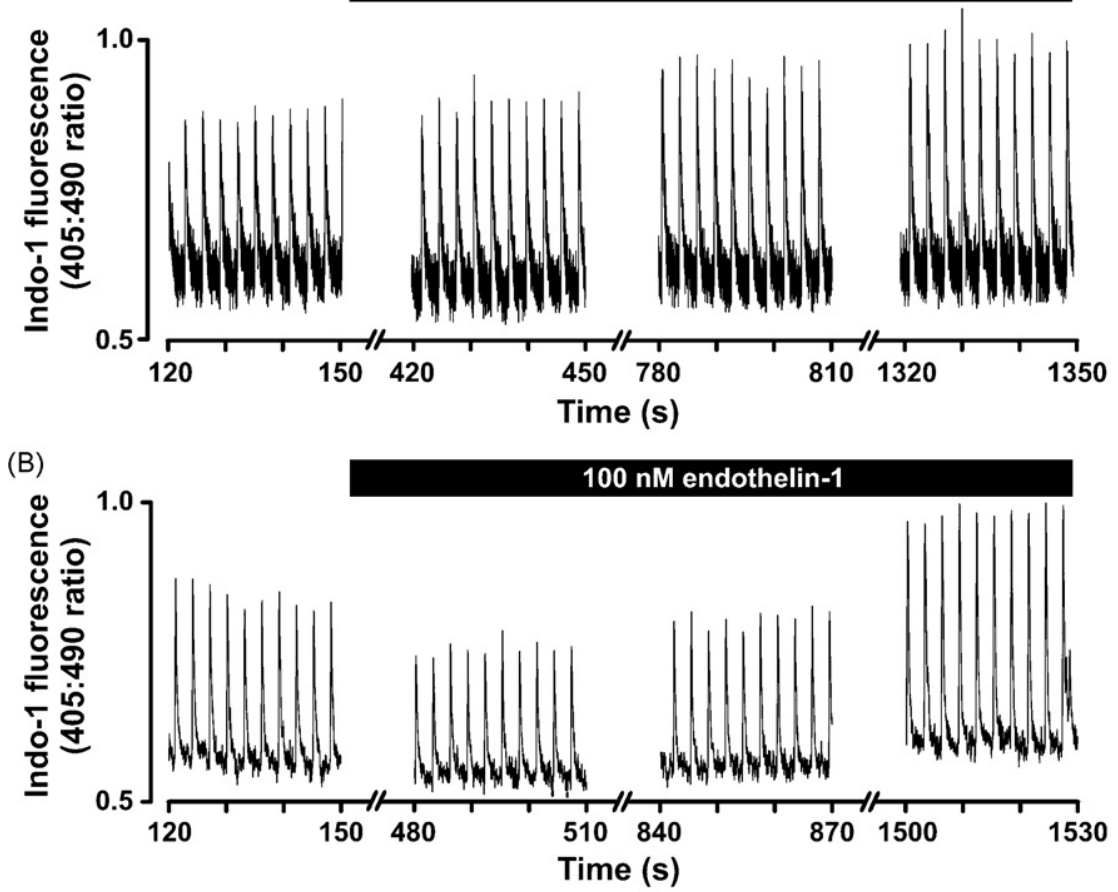

(Ci)

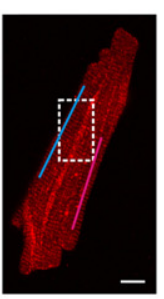

(Di)

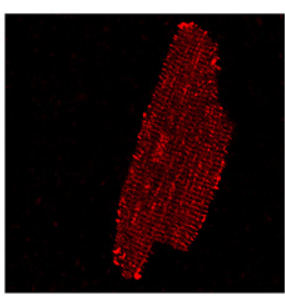

(Ei)

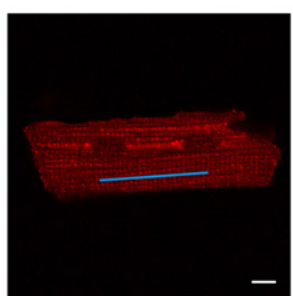

(ii)

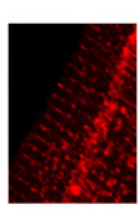

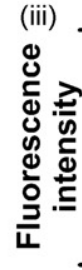

(iii)
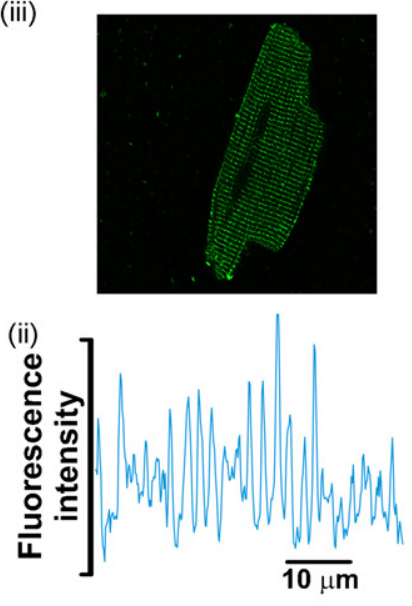

(iv)

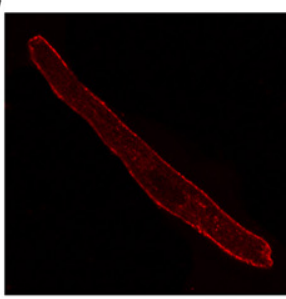

(iii)

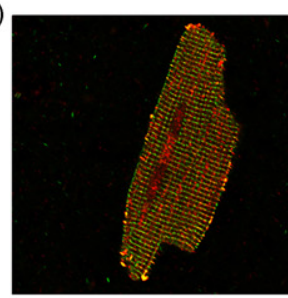

(F)

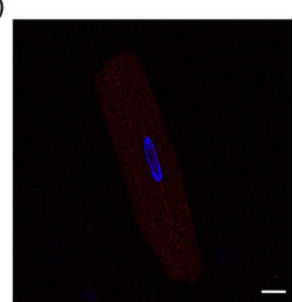

Fig. 6. Endothelin-1 evoked inotropy and receptor localisation. The traces in panels $\mathrm{A}$ and $\mathrm{B}$ depict typical patterns of $\mathrm{Ca}^{2+}$ response in single electrically paced ventricular (A) or atrial (B) myocytes. Panels C-E illustrate the spatial distribution of $\mathrm{ET}_{\mathrm{A}}$ receptors in a ventricular and an atrial myocyte. The image in panel (Ci) depicts $\mathrm{ET}_{\mathrm{A}}$ receptor

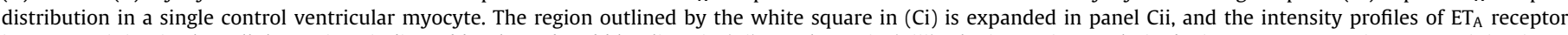
immunostaining in the cellular regions indicated by the red and blue lines in (Ci) are shown in (Ciii). The image in panel Civ depicts $\mathrm{ET}_{\mathrm{A}}$ receptor immunostaining in an atrial myocyte. Panels Di-iii depict a single ventricular myocytes that was co-immunostained for $\mathrm{ET}_{\mathrm{A}}$ receptors (Di) and RyRs (Dii). A superimposed image of $\mathrm{ET}_{\mathrm{A}}$ receptor and RyR immunofluorescence is shown in (Diii). Panel Ei illustrates $\mathrm{ET}_{\mathrm{A}}$ receptor immunostaining in a detubulated ventricular myocyte. The intensity profile of $\mathrm{ET}_{\mathrm{A}}$ receptor immunostaining in the cellular region indicated by the blue line in (Ei) is shown in (Eii). Panel F illustrates the typical immunostaining obtained when cells were treated with the anti-ET $\mathrm{A}_{\mathrm{A}}$ receptor antibody in the presence of the peptide sequence to which the antibody was raised. The white bars in the cell images represent $10 \mu \mathrm{m}$. The data are representative of $>10$ cells for each condition, sampled from at least three independent preparations. 
The traces presented in Fig. 4A and C, from control ventricular and atrial myocytes respectively, suggest that $\mathrm{Ca}^{2+}$ transients in ventricular cells have a greater amplitude and longer duration than in their atrial counterparts. These observations, obtained using confocal line-scanning of fluo-4-loaded myocytes, were confirmed using ratiometric photometry recording of indo- 1 fluorescence from individual paced cells. Ventricular myocytes displayed an average peak systolic indo- 1 ratio of $1.29 \pm 0.15$ (405:490 nm ratio) and a full-width at half-maximal amplitude of $530 \pm 63 \mathrm{~ms}(n=16)$. Under the same stimulation and recording conditions, the systolic indo-1 signal in atrial myocytes was 0.84 \pm 0.1 (405:490 ratio; $n=16$ ), and a full-width at half-maximal amplitude of $336 \pm 14 \mathrm{~ms}$.

\subsection{Effect of detubulation on hormonal responses}

The inotropic status of cardiac myocytes is regulated by numerous hormonal inputs. In particular, the peptide hormone endothelin-1 (ET-1) can promote acute changes in $\mathrm{Ca}^{2+}$ signalling and contractility within both ventricular and atrial myocytes. We explored the relationship between the tubule systems in ventricular and atrial myocytes and responsiveness to ET-1. Typical ventricular and atrial cell responses to ET-1 are presented in Fig. 6A and B respectively ( $n>30$ cells of each type). Essentially, ET-1 application stimulated a progressive positive inotropic effect, whereby the amplitude of the systolic (and sometimes diastolic) $\mathrm{Ca}^{2+}$ levels was elevated, and concomitantly the cells contracted to a greater extent. This positive inotropic effect of ET-1 was observed in all atrial myocytes and $>90 \%$ of ventricular myocytes. In some cells, whether ventricular or atrial, the positive inotropic action of ET-1 was delayed by a brief negative inotropic phase where the amplitude of the systolic $\mathrm{Ca}^{2+}$ signals (and contractility) was decreased. But even in those cells, positive inotropy eventually superseded the negative phase.

$\mathrm{ET}_{\mathrm{A}}$ receptors are abundantly expressed on ventricular myocytes (Fig. 6Ci), and have a transverse striated appearance with the same spacing as T-tubule membranes (Fig. 6Cii and iii). Indeed, the distribution of $\mathrm{ET}_{\mathrm{A}}$ receptors had a strong overlap with RyRs, confirming that they are present in tubular membranes (Fig. 6D; Pearson's correlation coefficient $0.45 ; n=3$ regions sample from three different cells). There was no significant $\mathrm{ET}_{\mathrm{A}}$ receptor immunostaining around the cells' periphery (Fig. 6Ci and ii). Detubulation did not diminish the extent of immunostaining observed with the anti-ET $\mathrm{A}_{\mathrm{A}}$ receptor antibody. However, the striated distribution of $\mathrm{ET}_{\mathrm{A}}$ receptors was marginally less regular after detubulation (Fig. 6E). The location of the $\mathrm{ET}_{\mathrm{A}}$ receptors was still positively correlated with that or RyRs, albeit to a lesser extent than in control ventricular myocytes (Pearson's correlation coefficient $0.2 ; n=3$ regions sample from three different cells). The specificity of the anti-ET $\mathrm{E}_{\mathrm{A}}$ receptor antibody was confirmed using a blocking peptide (Fig. $6 \mathrm{~F}$ ). With atrial myocytes, $\mathrm{ET}_{\mathrm{A}}$ receptor immunostaining was evident around the entire sarcolemma. In addition, there was some diffuse irregular $\mathrm{ET}_{\mathrm{A}}$ receptor staining within the centre of the cells (Fig. 6Civ).
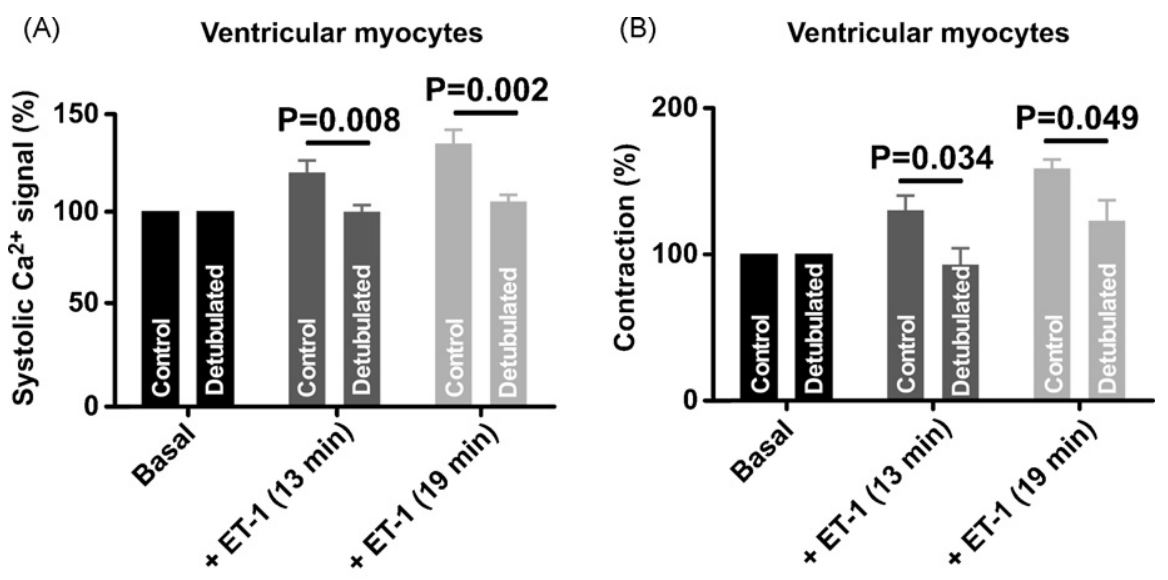

(C) Ventricular myocytes

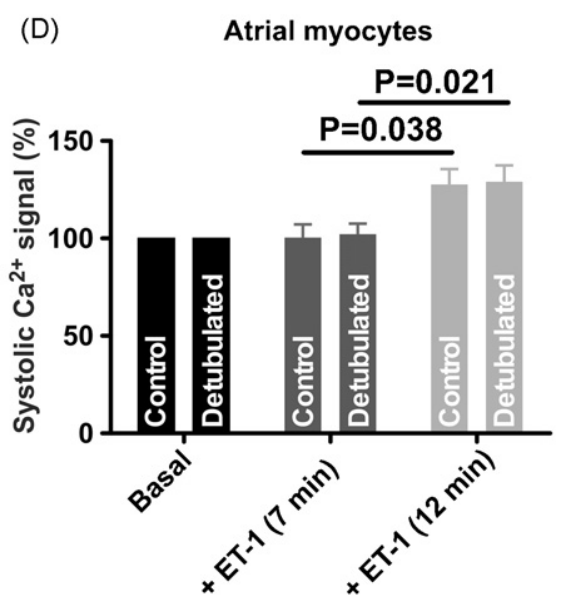

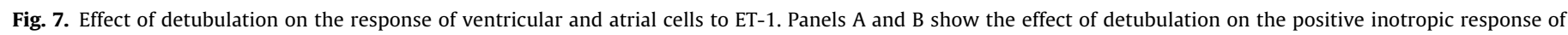

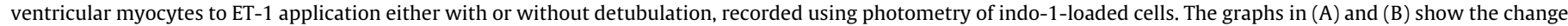

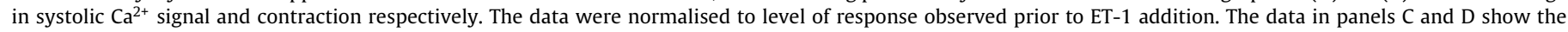

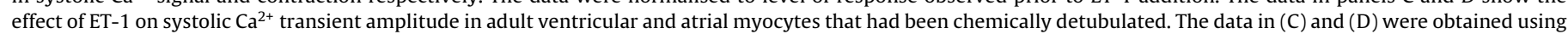
confocal imaging of fluo-4-loaded cells. The data represent mean $\pm \operatorname{SEM}$ ( $n=12$ for each condition). 

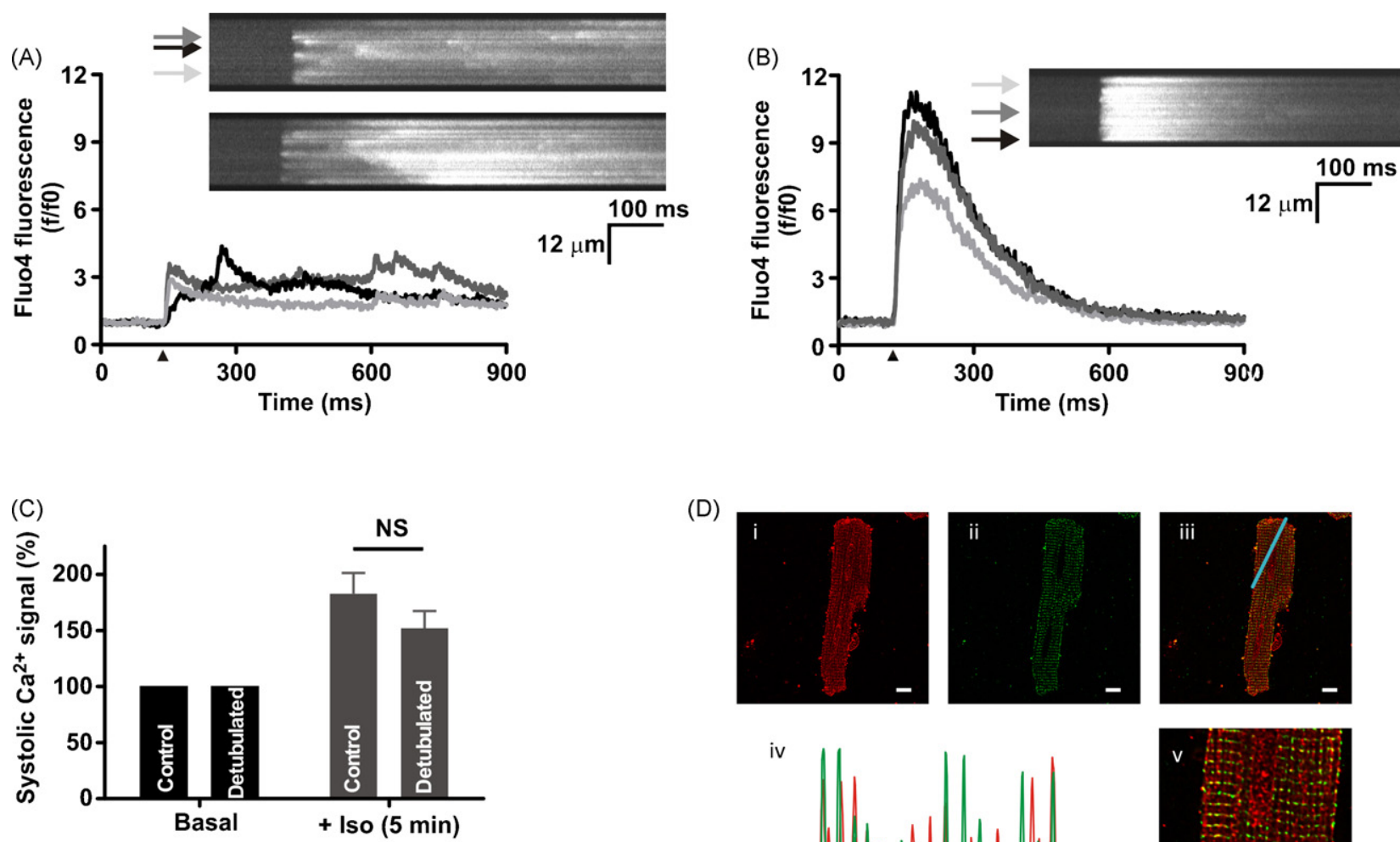

(D)
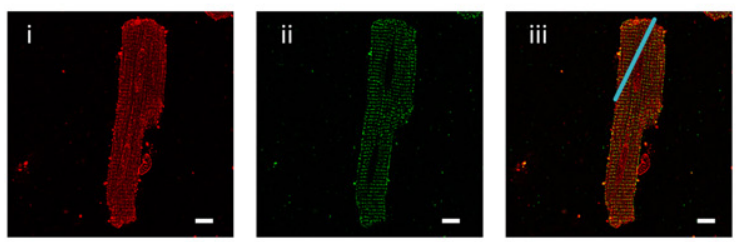

iv
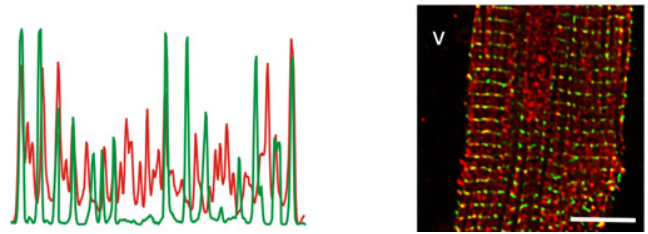

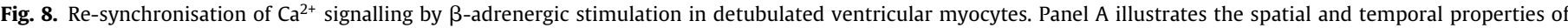

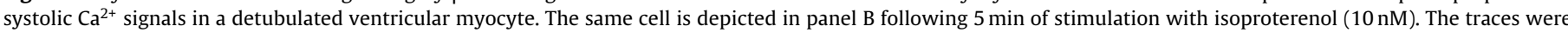

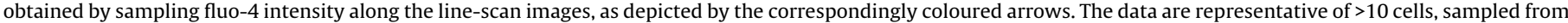

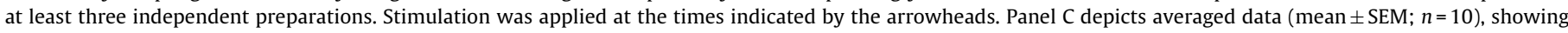

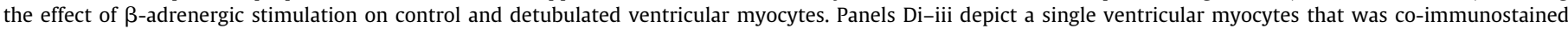

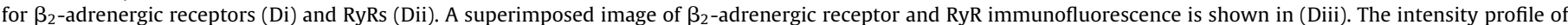

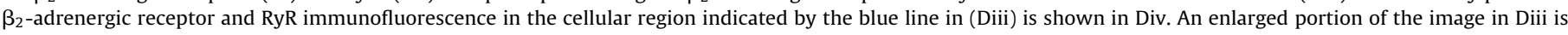
presented in Div. The white bars in the cell images represent $10 \mu \mathrm{m}$.

Detubulation of ventricular myocytes completely prevented the inotropic effects of ET-1. Application of ET-1 to detubulated cells did not significantly change either the systolic $\mathrm{Ca}^{2+}$ transient amplitude (Fig. 7A and C, photometry and confocal readings respectively; $n=12$ for each condition) or contraction (Fig. $7 \mathrm{~B} ; n=12$ ). In contrast, the response of atrial myocytes to ET- 1 was unaffected by the detubulation protocol (Fig. 7D; $n=12$ ).

Whereas the response to ET- 1 was completely abrogated by detubulation of ventricular myocytes, the positive inotropy triggered following activation of $\beta$-adrenergic receptors was less affected. Fig. 8A depicts the response of a detubulated ventricular myocyte to field stimulation. It is evident that this cell struggled to mount a co-ordinated $\mathrm{Ca}^{2+}$ signal. Rather, there was a persistent stochastic activation of $\mathrm{Ca}^{2+}$ spark sites that produced a systolic $\mathrm{Ca}^{2+}$ transient of low amplitude that persisted for a considerable time. Application of isoproterenol $(10 \mathrm{nM})$ for $5 \mathrm{~min}$ altered the pattern of response such that a rapid homogenous $\mathrm{Ca}^{2+}$ transient was observed upon depolarisation (Fig. 8B). Individual $\mathrm{Ca}^{2+}$ sparks were no longer evident, and the $\mathrm{Ca}^{2+}$ transient recovered to diastolic levels rapidly. Similar effects of $\beta$-adrenergic stimulation were seen in most ventricular myocytes irrespective of whether they had been detubulated or not (Fig. 8C; $n=10$ ). Immunostaining ventricular myocytes for $\beta_{2}$-adrenergic receptors indicated that they were expressed both within and around the circumference of the cells (Fig. 8D). Within the cells, the $\beta_{2}$-adrenergic receptor immunostaining was observed in close spatial correlation to RyRs, suggesting that they were localised on T-tubule membranes (Fig. 8D; Pearson's correlation coefficient $0.22 \pm 0.03$ ). There was also some $\beta_{2}$-adrenergic receptor immunostaining distinct from RyRs. Detubulation did not alter the distribution of $\beta_{2}$-adrenergic receptors relative to RyRs ( $n=6$ for each condition; Pearson's correlation coefficient $0.2 \pm 0.01$ ).

We have previously shown that isoproterenol acts as a positive inotropic agent for atrial myocytes by increasing the centripetal of $\mathrm{Ca}^{2+}$ transients in atrial myocytes. In atrial myocytes stimulated with isoproterenol, the $\mathrm{Ca}^{2+}$ signal that originates in the subsarcolemmal region at the on-set of EC-coupling faithfully propagates into the centre of the cells and thereby enhances contractility [13]. The detubulation process did not alter the response of atrial myocytes to isoproterenol. Following isoproterenol treatment both control and formamide-treated atrial myocytes displayed global $\mathrm{Ca}^{2+}$ transients where the $\mathrm{Ca}^{2+}$ signal fully propagated to the centre of the cells ( $n=6$; data not shown).

\section{Discussion}

In the present study, we sought to examine the functional roles of T-tubules in rat atrial and ventricular myocytes. A comparative study of T-tubule location and function in these major cardiac cells types has not been performed previously. The highly ordered T-tubules in mammalian ventricular myocytes are known to be the location of key proteins involved in EC-coupling and $\mathrm{Ca}^{2+}$ homeostasis [5]. However, much less is known about the expression and function of sarcolemmal tubules in atrial cells. Although it is commonly cited that mammalian atrial myocytes 
do not possess T-tubules $[5,9,26]$, it has been suggested that these cells possess a rudimentary transverse-axial tubular system [21-23,25,33]. Results obtained from immunostaining (Fig. 1C), membrane labelling with Di-8-ANNEPS (Fig. 2D) and $\mathrm{Ca}^{2+}$ imaging (Fig. 3D) concur with the notion that some atrial myocytes have tubule membranes that can initiate EC-coupling deep within the cytosol. The presence of the T-tubules accelerated the on-set of $\mathrm{Ca}^{2+}$ signals within the centre of atrial myocytes and increased $\mathrm{Ca}^{2+}$ transient amplitude (Figs 3 and 4Figs. 3D and 4). Although there was a more synchronous initiation of systolic $\mathrm{Ca}^{2+}$ signals in atrial cells with ' $W$ '-shaped $\mathrm{Ca}^{2+}$ transients, their overall rate of rise was not dissimilar from the major population of cells that had ' $U$ 'shaped $\mathrm{Ca}^{2+}$ signals (Fig. 3F). This was due to a secondary phase of CICR in the T-tubule-expressing atrial cells, which initiated tens of milliseconds after the initial depolarisation and slowed the overall kinetics of the $\mathrm{Ca}^{2+}$ signal. This secondary CICR phase is evident in the line-scan image and traces in Fig. 3D. Atrial myocytes with T-tubules therefore show larger systolic $\mathrm{Ca}^{2+}$ transients that reach peak more slowly due to an enhanced trigger for CICR from the non-junctional RyRs. In contrast, atrial cells without T-tubules did not show marked CICR in the central regions. Rather, there was a progressively diminishing centripetal movement of $\mathrm{Ca}^{2+}$ (Fig. 3C), consistent with a non-regenerative inward diffusion of $\mathrm{Ca}^{2+}[4,30]$.

It is well established that a major mechanism for recovery of $\mathrm{Ca}^{2+}$ transients in ventricular myocytes is sarcolemmal $\mathrm{Na}^{+} / \mathrm{Ca}^{2+}$ exchange, which has been suggested to be concentrated within Ttubule membranes [5,34]. The reduced recovery of $\mathrm{Ca}^{2+}$ transients in detubulated ventricular myocytes observed in this study (Fig. 4G) and others [8,32], is consistent with this hypothesis. Similarly, we found that the presence of T-tubules in atrial myocytes modestly accelerated the recovery of the $\mathrm{Ca}^{2+}$ transients (Fig. 4G), suggesting that in these cells the tubular membranes similarly allow more rapid removal of cytosolic $\mathrm{Ca}^{2+}$, plausibly by allowing $\mathrm{Na}^{+} / \mathrm{Ca}^{2+}$ exchange function deep within the cells. In addition, tubulated atrial cells displayed a faster recovery of systolic $\mathrm{Ca}^{2+}$ signals following SR depletion (Fig. 5). These data suggest that atrial T-tubules provide a conduit for $\mathrm{Ca}^{2+}$ exchange deep within the myocytes that can facilitate both recovery of $\mathrm{Ca}^{2+}$ signals and also refilling of $\mathrm{Ca}^{2+}$ stores. In both of these respects, atrial T-tubules have the same functions as in their ventricular counterparts [32].

Rather than producing homogenous systolic $\mathrm{Ca}^{2+}$ transients, detubulated ventricular myocytes displayed $\mathrm{Ca}^{2+}$ waves (Fig. 3) and $\mathrm{Ca}^{2+}$ sparks (Fig. 8) with variable initiation sites and degrees of propagation. The lack of synchronous $\mathrm{Ca}^{2+}$ release in detubulated ventricular myocytes is not due to displacement of RyRs (Fig. 1), or lack of SR $\mathrm{Ca}^{2+}$ loading [27,32]. In this study, the most common pattern of response observed in detubulated ventricular myocytes was ' $U$ '-shaped $\mathrm{Ca}^{2+}$ waves originating at both edges of a cell (Fig. 3B). Such responses are reminiscent of atrial cell $\mathrm{Ca}^{2+}$ signals, and suggest that removal of T-tubules makes ventricular myocytes largely rely on peripheral VOCC/RyR couplings, and subsequent centripetal CICR, just like their atrial counterparts. However, whilst atrial myocytes are stereotypic in their pattern of response [11], detubulated ventricular myocytes were more variable with $\mathrm{Ca}^{2+}$ alternans appearing in a proportion of the cells (Fig. 3F). The variation of systolic $\mathrm{Ca}^{2+}$ concentration during the alternans was evident at the periphery of the cells, but even more so within the centre of the cell. These observations suggest that the peripheral VOCC/RyR couplings in ventricular myocytes do not have the same fidelity as in atrial cells, and are not able to consistently trigger the centripetal propagation of CICR. Consistent with this, it has been shown that the peripheral VOCC/RyR couplings in ventricular myocytes are functionally distinct from their T-tubule-located counterparts. They may be less well arranged for EC-coupling, but provide more $\mathrm{Ca}^{2+}$ influx during depolarisation for SR reloading $[35,36]$. It therefore appears that following detubu- lation, ventricular myocytes rely on relatively weaker VOCC/RyR couplings in their periphery, as compared to the deliberate physiological peripheral VOCC/RyR couplings of atrial myocytes.

The characteristics of atrial $\mathrm{Ca}^{2+}$ transients were markedly different from those recorded in ventricular myocytes. In agreement with a recent study from Trafford and colleagues [9], we observed that atrial myocyte $\mathrm{Ca}^{2+}$ transients were smaller and slower to peak than $\mathrm{Ca}^{2+}$ signals in control ventricular cells (Figs. 3 and 4). This was true for atrial myocytes displaying ' $U$ '- or ' $W$ '-shaped $\mathrm{Ca}^{2+}$ transients. In addition, the atrial responses recovered more rapidly (Fig. 4G), which is probably due to the greater degree of $\mathrm{Ca}^{2+}$ buffering in atrial myocytes [9]. Detubulation of ventricular myocytes did not make the kinetics of their $\mathrm{Ca}^{2+}$ signals resemble atrial responses. Rather, they displayed $\mathrm{Ca}^{2+}$ transients that were significantly slower in every respect (Fig. 4). In only one aspect did detubulated ventricular myocytes resemble atrial cells. That is, detubulation of ventricular myocytes decreased their systolic $\mathrm{Ca}^{2+}$ transient amplitude to levels observed in atrial myocytes with 'W'-shaped $\mathrm{Ca}^{2+}$ transients (Fig. 4). Our data indicate that atrial systolic $\mathrm{Ca}^{2+}$ transients are altered by the presence of $\mathrm{T}$ tubules. However, atrial $\mathrm{Ca}^{2+}$ transients do not resemble ventricular signals, even in those atrial cells expressing central initiation sites.

Ventricular and atrial myocytes reacted to ET-1 stimulation with similar patterns of response (Fig. $6 \mathrm{~A}$ and B). Both cell types displayed brief negative inotropic phases eventually leading to sustained positive inotropy, consistent with previous observations in various mammalian species [4,37-39]. However, the location at which ET-1-mediated signal transduction occurs is evidently different between the two cell types. The positive inotropic effect of ET-1 was completely lost in detubulated ventricular cells (Fig. 7A-C), whereas formamide treatment had no measurable effect on the response of atrial myocytes to ET-1 (Fig. 7D). These data indicate that T-tubules are the primary sites of ET-1 signal transduction in ventricular myocytes, consistent with the immunolocalisation of $\mathrm{ET}_{\mathrm{A}}$ receptors in tubule membranes (Fig. 6) [40-42]. In contrast, $\mathrm{ET}_{\mathrm{A}}$ receptors in atrial myocytes are primarily located at the periphery (Fig. 6Civ). It is plausible that some $\mathrm{ET}_{\mathrm{A}}$ receptors may be expressed on atrial cell T-tubules, but they evidently have a modest functional consequence (Fig. 7D).

The loss of T-tubules in ventricular myocytes leads to decreased synchrony of $\mathrm{Ca}^{2+}$ release, smaller $\mathrm{Ca}^{2+}$ transients and reduced contractility (Figs. 3, 7 and 8). Activation of cyclic AMP signalling, via $\beta$-adrenergic receptor stimulation, can reverse these effects and promote better temporal and spatial synchronisation of the systolic $\mathrm{Ca}^{2+}$ transient (Fig. 8) [26,43]. This synchronisation occurs even in extremely deleterious situations where detubulation has caused the cellular response to become fragmented into stochastic $\mathrm{Ca}^{2+}$ sparks (Fig. 8). We observed that $\beta_{2}$-adrenergic receptors were expressed both within ventricular myocytes, on T-tubule membranes, and around the circumference of the cells (Fig. 8D). This distribution is different to that of the $\mathrm{ET}_{\mathrm{A}}$ receptors, which were solely expressed in T-tubules (Fig. 6C). The difference in distribution patterns most likely explains why detubulation completely inhibited the inotropic affects of ET-1, but did not significantly alter the action of isoproterenol (Figs. 7 and 8). The population of $\beta_{2}$ adrenergic receptors expressed around the circumference of the ventricular myocytes appears to be sufficient to mediate the effects of isoproterenol.

It has been proposed that adrenergic signalling is compartmentalised at T-tubules within cardiac myocytes due to firewalls of specific phosphodiesterases that prevent the diffusion of cyclic AMP, as well as localisation of protein kinase A to specific targets $[44,45]$. However, the ability of isoproterenol to completely globalise $\mathrm{Ca}^{2+}$ signals in detubulated cells suggests that the range of cyclic AMP action must extend further than its proposed locality 
around T-tubules [46]. Similarly, for atrial myocytes $\beta$-adrenergic stimulation promoted a change from diminishing centripetal propagation of $\mathrm{Ca}^{2+}$ transients (Fig. 3C) to global $\mathrm{Ca}^{2+}$ transients [13]. Detubulation did not affect the response of atrial myocytes to isoproterenol (data not shown). This also supports the notion that cyclic AMP action extends away from its site of production at the peripheral sarcolemma, to promote $\mathrm{Ca}^{2+}$ release deep within atrial cells.

With acute detubulation method used in this study, isoproterenol was able to globalise the otherwise dys-synchronous $\mathrm{Ca}^{2+}$ transients (Fig. 8). The situation is different in situations where T-tubules are lost for prolonged periods, which is known to happen in ageing and during pathological development of the heart. For example, in myocytes from ischemic pig hearts $\beta$-adrenergic stimulation cannot synchronise $\mathrm{Ca}^{2+}$ release in regions devoid of T-tubules [47]. This suggest that acute detubulation, such as that used in this study, is functionally rather different from longerterm detubulation. Formamide treatment causes the T-tubules to be rapidly fragmented, but the membranes re-seal and are acutely retained in the cell, along with their adjacent RyR-bearing SR (Figs. 1 and 2). In contrast, with prolonged T-tubule loss, the cellular region becomes unresponsive to either EC-coupling or the synchronising inotropic effects of $\beta$-adrenergic stimulation $[47,48]$.

In summary, we have shown that atrial myocytes, like their ventricular counterparts, can express invaginations of the sarcolemma consistent with a transverse-axial tubular system. Ventricular myocytes are highly dependent on their regular T-tubules for the synchronised high-fidelity EC-coupling and response to some hormonal agonists. In contrast, the relatively sparse and irregular Ttubules in atrial myocytes have a more subtle effect on EC-coupling, and little apparent action in hormonal signal transduction. The correlation between atrial cell width and T-tubule expression (Fig. 2E) suggests that the physiological significance of the tubules is to promote the synchrony of contraction and recovery within the atrial chambers.

\section{Acknowledgements}

This work was funded by the BBSRC and British Heart Foundation (grant number PG/06/034/20637). IS is funded by a BBSRC studentship. HLR is a Royal Society Research Fellow.

\section{References}

[1] D.M. Bers, Cardiac excitation-contraction coupling, Nature 415 (2002) 198-205.

[2] D.A. Eisner, T. Kashimura, S.C. O'Neill, L.A. Venetucci, A.W. Trafford, What role does modulation of the ryanodine receptor play in cardiac inotropy and arrhythmogenesis? J. Mol. Cell. Cardiol. (2008).

[3] G. Antoons, K.R. Sipido, Targeting calcium handling in arrhythmias, Europace 10 (2008) 1364-1369.

[4] M.D. Bootman, D.R. Higazi, S. Coombes, H.L. Roderick, Calcium signalling during excitation-contraction coupling in mammalian atrial myocytes, J. Cell Sci. 119 (2006) 3915-3925.

[5] C. Orchard, F. Brette, t-Tubules and sarcoplasmic reticulum function in cardiac ventricular myocytes, Cardiovasc. Res. 77 (2008) 237-244.

[6] N. Tohse, S. Seki, T. Kobayashi, M. Tsutsuura, M. Nagashima, Y. Yamada, Development of excitation-contraction coupling in cardiomyocytes, Jpn. J. Physiol. $54(2004) 1-6$

[7] C. Soeller, M.B. Cannell, Examination of the transverse tubular system in living cardiac rat myocytes by 2-photon microscopy and digital image-processing techniques, Circ. Res. 84 (1999) 266-275.

[8] M.R. Fowler, R.S. Dobson, C.H. Orchard, S.M. Harrison, Functional consequences of detubulation of isolated rat ventricular myocytes, Cardiovasc. Res. 62 (2004) 529-537.

[9] A.P. Walden, K.M. Dibb, A.W. Trafford, Differences in intracellular calcium homeostasis between atrial and ventricular myocytes, J. Mol. Cell. Cardiol. (2008).

[10] S.L. Carl, K. Felix, A.H. Caswell, N.R. Brandt, W.J. Ball Jr., P.L. Vaghy, G. Meissner, D.G. Ferguson, Immunolocalization of sarcolemmal dihydropyridine receptor and sarcoplasmic reticular triadin and ryanodine receptor in rabbit ventricle and atrium, J. Cell Biol. 129 (1995) 672-682.
[11] L. Mackenzie, M.D. Bootman, M.J. Berridge, P. Lipp, Predetermined recruitment of calcium release sites underlies excitation-contraction coupling in rat atrial myocytes, J. Physiol. 530 (2001) 417-429.

[12] J. Kockskamper, K.A. Sheehan, D.J. Bare, S.L. Lipsius, G.A. Mignery, L.A. Blatter, Activation and propagation of $\mathrm{Ca}(2+)$ release during excitation-contraction coupling in atrial myocytes, Biophys. J. 81 (2001) 2590-2605.

[13] L. Mackenzie, H.L. Roderick, M.J. Berridge, S.J. Conway, M.D. Bootman, The spatial pattern of atrial cardiomyocyte calcium signalling modulates contraction, J. Cell Sci. 117 (2004) 6327-6337.

[14] K.A. Sheehan, A.V. Zima, L.A. Blatter, Regional differences in spontaneous Ca2+ spark activity and regulation in cat atrial myocytes, J. Physiol. 572 (2006) 799-809.

[15] S.H. Woo, L. Cleemann, M. Morad, Ca2+ current-gated focal and local Ca2+ release in rat atrial myocytes: evidence from rapid 2-D confocal imaging, J. Physiol. 543 (2002) 439-453.

[16] J.R. Berlin, Spatiotemporal changes of Ca2+ during electrically evoked contractions in atrial and ventricular cells, Am. J. Physiol. 269 (1995) H1165-H1170.

[17] P. Lipp, L. Pott, G. Callewaert, E. Carmeliet, Simultaneous recording of Indo1 fluorescence and $\mathrm{Na}^{+} / \mathrm{Ca}^{2+}$ exchange current reveals two components of $\mathrm{Ca} 2(+)$-release from sarcoplasmic reticulum of cardiac atrial myocytes, FEBS Lett. 275 (1990) 181-184.

[18] K.A. Sheehan, L.A. Blatter, Regulation of junctional and non-junctional sarcoplasmic reticulum calcium release in excitation-contraction coupling in cat atrial myocytes, J. Physiol. 546 (2003) 119-135.

[19] S.N. Hatem, A. Benardeau, C. Rucker-Martin, I. Marty, P. de Chamisso, M. Villaz, J.J. Mercadier, Different compartments of sarcoplasmic reticulum participate in the excitation-contraction coupling process in human atrial myocytes, Circ. Res. 80 (1997) 345-353.

[20] M.D. Bootman, D. Harzheim, I. Smyrnias, S.J. Conway, H.L. Roderick, Temporal changes in atrial EC-coupling during prolonged stimulation with endothelin-1 Cell Calcium 42 (2007) 489-501.

[21] T. Gotoh, Quantitative studies on the ultrastructural differentiation and growth of mammalian cardiac muscle cells. The atria and ventricles of the cat, Acta Anat. (Basel) 115 (1983) 168-177.

[22] A.S. Ayettey, V. Navaratnam, The T-tubule system in the specialized and general myocardium of the rat, J. Anat. 127 (1978) 125-140.

[23] J.G. Tidball, J.E. Cederdahl, D.M. Bers, Quantitative analysis of regional variability in the distribution of transverse tubules in rabbit myocardium, Cell Tissue Res. 264 (1991) 293-298.

[24] T.S. Leeson, T-tubules, couplings and myofibrillar arrangements in rat atrial myocardium, Acta Anat. (Basel) 108 (1980) 374-388.

[25] M.M. Kirk, L.T. Izu, Y. Chen-Izu, S.L. McCulle, W.G. Wier, C.W. Balke, S.R. Shorofsky, Role of the transverse-axial tubule system in generating calcium sparks and calcium transients in rat atrial myocytes, J. Physiol. 547 (2003) 441451.

[26] F. Brette, K. Komukai, C.H. Orchard, Validation of formamide as a detubulation agent in isolated rat cardiac cells, Am. J. Physiol. Heart Circ. Physiol. 283 (2002) H1720-H1728.

[27] M. Kawai, M. Hussain, C.H. Orchard, Excitation-contraction coupling in rat ventricular myocytes after formamide-induced detubulation, Am. J. Physiol. 277 (1999) H603-H609.

[28] D.R. Higazi, C.J. Fearnley, F.M. Drawnel, A. Talasila, E.M. Corps, O. Ritter, F. McDonald, K. Mikoshiba, M.D. Bootman, H.L. Roderick, Endothelin-1stimulated InsP3-induced $\mathrm{Ca}^{2+}$ release is a nexus for hypertrophic signaling in cardiac myocytes, Mol. Cell 33 (2009) 472-482.

[29] S. Bolte, F.P. Cordelieres, A guided tour into subcellular colocalization analysis in light microscopy, J. Microsc. 224 (2006) 213-232.

[30] L.A. Blatter, J. Kockskamper, K.A. Sheehan, A.V. Zima, J. Huser, S.L. Lipsius, Local calcium gradients during excitation-contraction coupling and alternans in atrial myocytes, J. Physiol. 546 (2003) 19-31.

[31] Y. Chen-Izu, S.L. McCulle, C.W. Ward, C. Soeller, B.M. Allen, C. Rabang, M.B. Cannell, C.W. Balke, L.T. Izu, Three-dimensional distribution of ryanodine receptor clusters in cardiac myocytes, Biophys. J. 91 (2006) 1-13.

[32] F. Brette, S. Despa, D.M. Bers, C.H. Orchard, Spatiotemporal characteristics of SR $\mathrm{Ca}(2+)$ uptake and release in detubulated rat ventricular myocytes, J. Mol. Cell. Cardiol. 39 (2005) 804-812.

[33] F. Brette, C. Orchard, T-tubule function in mammalian cardiac myocytes, Circ Res. 92 (2003) 1182-1192.

[34] Z. Yang, C. Pascarel, D.S. Steele, K. Komukai, F. Brette, C.H. Orchard, $\mathrm{Na}^{+}-\mathrm{Ca}^{2+}$ exchange activity is localized in the T-tubules of rat ventricular myocytes, Circ. Res. 91 (2002) 315-322.

[35] F. Brette, L. Salle, C.H. Orchard, Quantification of calcium entry at the T-tubules and surface membrane in rat ventricular myocytes, Biophys. J. 90 (2006) 381-389.

[36] F. Brette, L. Salle, C.H. Orchard, Differential modulation of L-type $\mathrm{Ca}^{2+}$ current by $\mathrm{SR} \mathrm{Ca}^{2+}$ release at the T-tubules and surface membrane of rat ventricular myocytes, Circ. Res. 95 (2004) e1-7.

[37] B. Pieske, B. Beyermann, V. Breu, B.M. Loffler, K. Schlotthauer, L.S. Maier, S. Schmidt-Schweda, H. Just, G. Hasenfuss, Functional effects of endothelin and regulation of endothelin receptors in isolated human nonfailing and failing myocardium, Circulation 99 (1999) 1802-1809.

[38] A. Proven, H.L. Roderick, S.J. Conway, M.J. Berridge, J.K. Horton, S.J. Capper, M.D. Bootman, Inositol 1,4,5-trisphosphate supports the arrhythmogenic action of endothelin-1 on ventricular cardiac myocytes, J. Cell Sci. 119 (2006) 3363-3375. 
[39] I. Namekata, S. Fujiki, Y. Kawakami, R. Moriwaki, K. Takeda, T. Kawanishi, A. Takahara, K. Shigenobu, H. Tanaka, Intracellular mechanisms and receptor types for endothelin-1-induced positive and negative inotropy in mouse ventricular myocardium, Naunyn Schmiedebergs Arch. Pharmacol. 376 (2008) 385-395.

[40] K.Y. Chung, M. Kang, J.W. Walker, Contractile regulation by overexpressed ETA requires intact $\mathrm{T}$ tubules in adult rat ventricular myocytes, Am. J. Physiol. Heart Circ. Physiol. 294 (2008) H2391-H2399.

[41] V.G. Robu, E.S. Pfeiffer, S.L. Robia, R.C. Balijepalli, Y. Pi, T.J. Kamp, J.W. Walker, Localization of functional endothelin receptor signaling complexes in cardiac transverse tubules, J. Biol. Chem. 278 (2003) 48154-48161.

[42] B. Boivin, L.R. Villeneuve, N. Farhat, D. Chevalier, B.G. Allen, Sub-cellular distribution of endothelin signaling pathway components in ventricular myocytes and heart: lack of preformed caveolar signalosomes, J. Mol. Cell. Cardiol. 38 (2005) 665-676

[43] F. Brette, P. Rodriguez, K. Komukai, J. Colyer, C.H. Orchard, beta-Adrenergic stimulation restores the Ca transient of ventricular myocytes lacking t-tubules, J. Mol. Cell. Cardiol. 36 (2004) 265-275.
[44] R. Fischmeister, L.R. Castro, A. Abi-Gerges, F. Rochais, J. Jurevicius, J. Leroy, G. Vandecasteele, Compartmentation of cyclic nucleotide signaling in the heart: the role of cyclic nucleotide phosphodiesterases, Circ. Res. 99 (2006) 816-828.

[45] G. Di Benedetto, A. Zoccarato, V. Lissandron, A. Terrin, X. Li, M.D. Houslay, G.S. Baillie, M. Zaccolo, Protein kinase A type I and type II define distinct intracellular signaling compartments, Circ. Res. 103 (2008) 836-844.

[46] M. Zaccolo, T. Pozzan, Discrete microdomains with high concentration of cAMP in stimulated rat neonatal cardiac myocytes, Science 295 (2002) 1711-1715.

[47] F.R. Heinzel, V. Bito, L. Biesmans, M. Wu, E. Detre, F. von Wegner, P. Claus, S. Dymarkowski, F. Maes, J. Bogaert, F. Rademakers, J. D’Hooge, K. Sipido, Remodeling of T-tubules and reduced synchrony of $\mathrm{Ca}^{2+}$ release in myocytes from chronically ischemic myocardium, Circ. Res. 102 (2008) 338-346.

[48] W.E. Louch, V. Bito, F.R. Heinzel, R. Macianskiene, J. Vanhaecke, W. Flameng, K. Mubagwa, K.R. Sipido, Reduced synchrony of $\mathrm{Ca}^{2+}$ release with loss of T-tubules-a comparison to $\mathrm{Ca}^{2+}$ release in human failing cardiomyocytes, Cardiovasc. Res. 62 (2004) 63-73. 